\title{
Studying influence and accounting use-Empirical evidence about individual managers and organizations with changes in Galician healthcare
}

\author{
Derek E. Purdy ${ }^{\mathrm{a}, *}$, Susana Gago ${ }^{\mathrm{b}}$ \\ a Department of Management, University of Reading, PO Box 218, \\ Reading RG6 6AA, United Kingdom \\ b Department of Economía de la Empresa, University Carlos III de Madrid, \\ Calle Madrid, 126, 28903 Getafe, Madrid, Spain
}

Received 1 August 2005; received in revised form 9 February 2007; accepted 30 March 2007

\begin{abstract}
Legislation outlined proposed changes in Galician Health Centres. This allowed us to set down the theory about personal and organizational Information-Influence Matrices and then Frameworks of Issues for the interactions between an individual Financial Manager and a Health Centre Coordinator, as well as the proposed organizational changes into a new system [Purdy DE, Gago S. Extending influence and accounting use: developing the frameworks to incorporate Galician legal matters about the proposed healthcare changes with managers and organizations for empirical study. Critical Perspectives on Accounting; in press].

Evidence from a longitudinal study covering January 1997 and December 2001, indicated the suitability of these types of Matrices and Frameworks of Issues to analyse conversational data.

Results agreed with anticipations at a personal level-wholly for a co-ordinator and partly for the Financial Manager. Differences between the findings and our anticipated Financial Manager's framework are straightforward and we have amended our Framework accordingly. The organization level has followed our anticipations though only $15 \%$ of Health Centres had continued with the new system, $85 \%$ remained working with the old system.
\end{abstract}

\footnotetext{
* Corresponding author. Tel.: +44 1183785048.

E-mail addresses: D.E.Purdy@ reading.ac.uk (D.E. Purdy), sgago@emp.uc3m.es (S. Gago).
} 
Galician law contained aspirations for changing healthcare with autonomous Health Centres. Spanish health policies and budget laws have inhibited moves to change, as well as the actions of the professionals involved.

(C) 2007 D.E. Purdy. Published by Elsevier Ltd. All rights reserved.

Keywords: Information and influence; Consultation and Participation; Autonomy; Managers; Galician Health Centre Management; Personal construct psychology; Information-Influence Matrix; Organizational change; Accounting data

\section{Introduction}

The authors became aware and interested in the proposed Galician Health Centre reforms due to one author discussing our theoretical and empirical approaches used in previous studies (Purdy, 1993a, 1993b; Purdy and Gago, 2002) with a member of the Galician Health Service. In 1999, the authors sought access to upper Financial Managers and Health Centre Managers to study what was happening with these reforms but they had no detailed knowledge about the legal background to these.

With the prospect of being granted access to study the Galician Health Centre reforms over a number of years, we set out our general theoretical ideas about how we anticipated these reforms would affect matters. We drew up a theoretical paper which detailed our concepts about a Matrix of Information and Influence and a Framework of Issues which could be used at the level of the individual manager involved. These two theoretical concepts could be used to explain and detail the existing situations of the Financial Managers and the Health Centre Managers, the personnel most likely to be involved in the changes. That paper explained the changes likely to occur and affect the relationship between these managers (Purdy and Gago, 2003).

Next, we were granted access to monitor the non-medical aspects of the Galician Health Centre reforms with one Financial Manager and the Health Centre Managers for whom he was responsible. Finally, we were provided with the legislation which more finely indicated the changes which were anticipated for the management of the non-medical activities of Galician Health Centres. Since this legislation was different to our original general theoretical ideas, we amended our ideas to reflect this (Purdy and Gago, 2007).

The authors' interpretation of the legislation indicated the following matters. A Financial Manager, from the Galician regional level, was anticipated to move from an influence position of autonomy over the daily non-medical decisions at a Health Centre to a situation where the Financial Manager was the potential recipient of reports about the running of these decisions from a Health Centre Manager. We anticipated that the Financial Manager was likely to train a Health Centre Manager about the non-medical financial matters. During the time of working with the Health Centre Manager, it was anticipated that the Financial Manager would gradually handover the daily influence to a Health Centre Manager who would eventually be in a position of autonomous influence. One part of this process was that as the Financial Manager had less influence so the Health Centre Manager's influence increased (Purdy and Gago, in press). 
The conceptual bases used in our work come from the tradition of personal construct psychology where each individual has unique views (Kelly, 1955). In 1999 we had anticipated that our study of changes might take 5 or 6 years or even longer to implement, and anticipated we would seek to publish empirical findings at appropriate points in the future. The study was ended suddenly by the Galician Health Service in December 2001. This abrupt ending brought forward the need for an organizational analysis of these events using personal construction. Consequently, the revised paper went beyond the interpersonal analysis of the changes between two such managers and extended the analysis to include theoretical notions suitable to interpret the changes in the organizational/institutional arrangements considered at a personal level (Purdy and Gago, in press).

This paper contains the empirical evidence from individual managers about the reforms and changes in Galician healthcare due to be implemented between January 1997 and December 2001. As already mentioned two theoretical papers explained the theoretical bases of the ideas for comparison with the empirical materials reported in this paper (Purdy and Gago, 2003, in press). Those papers fully discussed the antecedents of these theories. This paper contains only a brief section about theory which essentially deals with the final theoretical individual situations for a Financial Manager, a Health Centre Manager, and the organizational level of analysis.

The paper's data comes from our interviews with managers. These materials have been compared with our anticipations at the individual level, a Financial Manager and a Health Centre Co-ordinator, and at the organizational level for the Health Centres. The majority of people involved in our work were male and so keeping to our practice we use the male form. The paper has the following structure.

The next section contains our brief theoretical perspectives. The third section discusses the approaches and methods for the field studies. The fourth main section contains the analysis of findings, whilst the fifth main section considers the implications of the empirical evidence for the authors' theoretical approach. A sixth main section considers the implications of the findings to the authors' norms, previously cited studies and other work, before the paper ends with a summary and conclusions.

\section{Theoretical perspectives}

\subsection{Prologue}

The stimulus for our research is an interest in the handling and use of financial management accounting information by managers in their work situations. We theorise about the activities of the individuals, obtain data from people at work then analyse and compare matters with the theory at the level of the individual. We offer a dynamic research framework in a very complex area (Purdy and Gago, in press).

The research follows the tradition of personal construct psychology established by Kelly. Amongst other things it accepts that each person has a unique view about life. There is a focus on the individual but, that there is commonality or similarity of views between individuals and also a sociality of views when a person understands the social processes of the other (Kelly, 1955). 
Here we are considering the handling and use of financial management accounting information by a dyad of managers. Initially in each dyad, one manager has much information and influence and the second manager has no information and no influence. Galician legislation has indicated that these situations will change and that a first manager (Financial Manager), who holds a position of autonomy, will eventually pass both specific information and specific influence to a second manager (Health Centre Manager), so that the second manager then holds an autonomous position. Each dyad will differ because the actions of an individual manager will relate to the specific work context. We concentrate on the constructs of Influence and Information that concern the individual managers in their own work situation, and relate this to an Information-Influence Matrix (Purdy and Gago, in press).

In the previous paper, the authors' basic theoretical positions and their antecedents were expounded then discussed. We moved from generalised theories and integrated our understanding of Galician legislation into our theoretical positions. These revisions were made in order to make the theory "a Galician anticipations/theory" so that this theory could be compared directly with our empirical materials. The authors were not aware of any directly comparable study but were aware that, elsewhere, moves towards changes in the provision of more information and more influence to employees had not occurred smoothly (Purdy, 1988). Following these amendments we discussed various matters and critiqued the work.

The discussion commented on retos (retos is explained and discussed with information later), the nature of other types of information, participative management notions, a Financial Manager and a Health Centre Manager, UK evidence concerning information and influence (Centre for Decision-Making Studies, 1979; Goodlad, 1984; Purdy, 1988), general European Economic Community views on information provision and employee involvement (European Communities Commission, 1994) and US evidence in the accounting area of our work (Arnold, 1999; Parker and Kyj, 2006; Scott and Tiessen, 1999; Spekman, 1979). In addition there were critical comments on the Galician context and similar changes elsewhere, including a critique of the underlying different cultural norms of each author in relation to Galicianization, the Galician quest for autonomy with Health Centres and the Galician identity in relation to our work.

We provided evidence about proposals for changes, to introduce more information provision to employees and more influence to employees in the European Community, the UK and the US, that were accompanied by strong narratives promoting the processes. The realities were that some changes did not occur, or had been altered, either before, during or after their introduction. In general the outcomes were more favourable for managers and less favourable for non-management employees.

The remainder of this section relates to the theoretical notions to be considered in the analysis of the empirical materials.

\subsection{Using the Information-Influence Matrix (Purdy and Gago, in press)}

\subsubsection{Introduction}

The Information-Influence Matrix is a representation of the position of an individual manager's views about information and influence in a specific relationship with another manager at one time. To demonstrate changes in each individual's position it is possible to 
use a Matrix showing discrete changes for a Financial Manager and a second Matrix for a Health Centre Manager.

Following from this, the Information-Influence Matrix can be used in a similar manner at the level of the Health Centre Organization. There is representation on a Matrix indicating the anticipated changes to the situations of the Health Centres. There was also the use of three Frameworks of Issues, to list the changes anticipated by the theory and specify the movements within each Matrix: for a Financial Manager, a Health Centre Manager and the Organization Issues for the Health Centres.

This theory paper considered that the provision of accounting information to an organization's managers and employees has fostered the provision and use of the information by these individuals. The social constructions of organizational activities engendered manager and employee involvement, along with manager and manager involvement, as possible conditions of influence. From these notions came the personal construction and social construction of an Information-Influence Matrix through which to develop understandings of the individual interactions of people at work.

\subsubsection{Influence}

The original construct of influence contained four markers: No Influence, Communication, Consultation and Participation (Purdy and Gago, 2003). When the changing situation between the two managers was reviewed, it was considered that the Financial Manager would already be in a position of Autonomy over the daily non-medical decisions of the Health Centre. We have included Autonomy as a fifth marker of influence. It is placed on our construct after Participation, as a form of participation; however, we are aware that it can be argued that Autonomy is a form of Consultation.

Our theoretical and operational definitions of influence are as follows.

- No Influence is the position where the manager is not allowed to exercise any influence in the organization in the formal sense, or perceives no obvious influence in the situation. A manager could influence matters by leaving the organization.

- Communication is a position where the first manager tells a second manager about a decision already taken, for example, by the first manager. The second manager might have the opportunity to formally express an opinion about the decision, but cannot directly influence the situation because the decision was already taken.

- Consultation is the position where the first manager provides information to the second manager about a situation, and the second manager has an opportunity to express an opinion to the first manager before the first manager takes the decision. Here the second manager could affect the first manager's decision because of the discussion.

- Participation is the position where the second manager receives information about a situation and discusses this with the first manager before they jointly take a decision, or take it in some manner which they jointly agreed previously. The second manager has the most opportunity to influence a situation, and for participation to happen, the first manager and second manager have to interact. Any information can come from either person.

- Participation requires the second manager to be an effective and active person capable of learning, as well as providing ideas and information. Information, influence and inter- 
action all appear to be necessary for participation to be in a state to occur (Purdy and Gago, 2003).

- Autonomy means that, a manager is able to act and take a decision alone without first referring to or conferring with another, at the time when the decision is taken. The manager exercising Autonomy may have referred to and conferred with others before the time when the decision was taken, and so be aware of the views of these others. In using the word Autonomy we consider the manager to have taken the decision in the context of the organization, so that this does not mean that the manager has personal freedom to act, but organizational freedom to act.

\subsubsection{Information}

The information construct contains four basic markers. The operation of the construct is based on the notion of decision distance with employees in a participative situation. Wall and Lischeron devised and tested the concept that an employee was aware of a distance that decisions were taken from their immediate job. They called the closest distance decisions such as related to the employee's job "Local". The decisions taken at a "Medium" distance from an employee could affect a department. The decisions taken furthest from an employee were "Distant" and could affect a whole organization (Wall and Lischeron, 1977).

These decision types were adapted to the concept of information in four areas. The markers are: No Information, Local Information, Medium Information and Distant Information. These markers were anticipated to be sufficient for our empirical work, but, we recognised that at the point when the Financial Manager has handed over autonomy to the Health Centre Manager then the Financial Manager would be in a different situation, and, would be a recipient of information from the Health Centre Manager. In this different situation there would still be Local Information, but it would be Different Local Information received by the Financial Manager.

The definitions of information are:

- No Information is the position where the manager perceives that no information is received or provided.

- Local Information is that information which exists for the current and immediate job at hand. It is a local decision for the manager and likely to be the smallest quantity of information.

- Medium Information is information for decisions further than the immediate job or the initial work activity. Decisions are taken at a medium distance from the manager and this information is likely to be more complex than local information.

- Distant Information, is any information used for decisions beyond medium decisions. Such decisions are taken at the furthest distance from the manager and probably use the most complex of information from any part of the organization.

We have introduced all of the components relating to a Matrix for our representations for the understanding of the Galician situations about a Financial Manager, a Health Centre Manager and the Health Centre as an Organization. All of these representations use a similar Matrix and the basic Galician Information-Influence Matrix is shown in Fig. 1. 


\begin{tabular}{|l|l|l|l|l|l|}
\hline \multirow{2}{*}{ Information } & \multicolumn{5}{|c|}{ Influence } \\
\cline { 2 - 6 } & No influence & Communication & Consultation & Participation & Autonomy \\
\hline Distant Information & & & & & \\
\hline Medium Information & & & & & \\
\hline Local Information & & & & & \\
\hline No information & & & & & \\
\hline
\end{tabular}

Fig. 1. Basic Galician Information-Influence Matrix.

\subsubsection{Information types}

After reviewing the Galician materials we concluded that a Financial Manager was anticipated to take all daily non-medical decisions after considering "all information". We were unable to define "all information" as we had no knowledge about the types of information likely to be available with a Health Centre.

Our review did indicate several areas of possible information matters that could affect the working contexts of the Financial Manager and the Health Centre Manager and thus affect the research Framework. For example, any changes concerning Health Centre activities had been anticipated to occur through the involvement of the community in which the Health Centre is located. It was acknowledged that changes were anticipated to occur without additional time or money being available. The legislation indicated that some professionals would have changes to remuneration, some individuals would work with retos and that information would be devised to examine the outcomes an individual's retos.

The word retos has no direct translation to English and was discussed and interpreted for the specific context of our study in the following three sentences. Retos relates to an area of activity where the area's objective is difficult to develop or carry out. For these reasons the retos constitutes a stimulus for the people who are trying to work in that area. A retos is somewhat intangible and a qualitative developmental aspect of life. We had no idea what types of retos would be used with a Financial Manager and a Health Centre Manager, but the legislation indicated objectives would be set and reported upon, thus creating some form of information. We had anticipated that such information could be used with an appropriate Information-Influence Matrix.

It was our anticipation that because of the Financial Manager's work, he would know which information he and other managers used in taking decisions about the daily activities of a Health Centre. In our terminology this would be Local Information but for the other areas we had no anticipations.

We now consider the specific anticipated changes for a Financial Manager and a Health Centre Manager.

\subsubsection{Anticipated changes of Information and Influence with a Financial Manager}

2.2.5.1. A Financial Manager's Personal Information-Influence Matrix. It is anticipated that the effect of these changes will alter the Framework of Issues on the Personal 


\begin{tabular}{|l|l|l|l|l|l|}
\hline \multirow{2}{*}{ Information } & \multicolumn{5}{|c|}{ Influence } \\
\cline { 2 - 6 } & No influence & Communication & Consultation & Participation & Autonomy \\
\hline $\begin{array}{l}\text { Distant } \\
\text { Information }\end{array}$ & & & & & \\
\hline $\begin{array}{l}\text { Medium } \\
\text { Information }\end{array}$ & & & & & \\
\hline Local Information & & 4 & 3 & 2 & 1 \\
\hline No information & & & & & \\
\hline
\end{tabular}

Fig. 2. Theoretical/anticipated movements of a Financial Manager in the Matrix relative to a Health Centre Manager.

Information-Influence Matrix of a Financial Manager. Over an unknown period it was anticipated that a Financial Manager will pass through five changes of information and influence. He will move from Autonomy using Local Health Centre Information, through Participation, Consultation and Communication on the Personal Information-Influence Matrix shown in Fig. 2.

When a Health Centre Manager achieves autonomy, the Financial Manager will have a different relationship with that manager. At the time a Health Centre Manager achieves autonomy a changed relationship between the managers would have occurred and the Health Centre Manager would then report about Local Different Information to the Financial Manager. We did not know what this Local Different Information might be. The changed relationship indicates a different Information-Influence Matrix for the Financial Manager with the Health Centre Manager, a position of Local Different Information and Communication, and is shown in Fig. 3. In this way a Financial Manager will have less influence upon the Health Centre's daily activities and a Health Centre Manager will have more influence.

\begin{tabular}{|l|l|l|l|l|l|}
\hline \multirow{2}{*}{ Information } & \multicolumn{5}{|c|}{ Influence } \\
\cline { 2 - 6 } & No influence & Communication & Consultation & Participation & Autonomy \\
\hline $\begin{array}{l}\text { Distant } \\
\text { Information }\end{array}$ & & & & & \\
\hline $\begin{array}{l}\text { Medium } \\
\text { Information }\end{array}$ & & & & & \\
\hline Local Information & & & & & \\
\hline $\begin{array}{l}\text { Local Different } \\
\text { Information }\end{array}$ & & 5 & & & \\
\hline No information & & & & & \\
\hline
\end{tabular}

Fig. 3. Theoretical/anticipated position of a Financial Manager after Health Centre Manager achieves Autonomy Matrix. 
2.2.5.2. A Financial Manager's Framework of Issues. The Framework of Issues and the movement on a Financial Manager's Matrix will be as follows:

1. Starts in the Local Information-Autonomy box.

2. After a period of time will interact with the Health Centre Manager and will be located in the Local Information-Participation box.

3. After a short period of time will interact with the Health Centre Manager and so will then be located in the Local Information-Consultation box.

4. After a further period of interaction will be located in the Local InformationCommunication box.

5. After a further period of interaction will be located in the Local Different Information-Communication box.

The changes in items 1-4, the anticipated movements of a Financial Manager in the Matrix in relation to a Health Centre Manager, are shown in Fig. 2. A Financial Manager would receive the Local Different Information, item 5, from a Health Centre Manager, as in Fig. 3.

\subsubsection{Anticipated changes of Information and Influence with a Health Centre Manager}

2.2.6.1. A Health Centre Manager's Personal Information-Influence Matrix. The Health Centre Manager's task is to gain Autonomy to be able to run the daily non-medical activities of the Health Centre. The extent to which this Autonomy occurs will relate to the Financial Manager and his requirements. It is anticipated that the Health Centre Manager will start without knowledge, information and influence but will acquire these and have Autonomy to run the Health Centre's daily activities. During this time the Health Centre Manager will obtain the necessary requirements from the Financial Manager or other forms of training.

The rate at which these changes will occur is not known and will be agreed with the Financial Manager. The Health Centre Manager will acquire various parts of Local Information and move through different stages of influence until Autonomy is reached. When the Health Centre Manager is involved with running the Health Centre, it seems likely that the Health Centre Manager will then become a source of different information for the Financial Manager about the Health Centre. Such a change could occur at any stage but, as we noted earlier, we have no clear views about these types of information.

The anticipated movements of these changes, for a Health Centre Manager on his personal Information-Influence Matrix, are shown in Fig. 4.

2.2.6.2. A Health Centre Manager's Framework of Issues. The Framework of Issues and changes on the Health Centre Manager's Matrix are:

1. Starts in the No Information-No Influence box.

2. After a short period of time will interact with the Financial Manager and so will then be located in the Local Information-Communication box.

3. After a further period of interaction will be located in the Local Information-Consultation box. 


\begin{tabular}{|l|l|l|l|l|l|}
\hline \multirow{2}{*}{ Information } & \multicolumn{5}{|c|}{ Influence } \\
\cline { 2 - 6 } & No influence & Communication & Consultation & Participation & Autonomy \\
\hline $\begin{array}{l}\text { Distant } \\
\text { Information }\end{array}$ & & & & & \\
\hline $\begin{array}{l}\text { Medium } \\
\text { Information }\end{array}$ & & & & & \\
\hline Local Information & & 2 & 3 & 4 & 5 \\
\hline No information & 1 & & & & \\
\hline
\end{tabular}

Fig. 4. Theoretical/anticipated movements of a Health Centre Manager on a Matrix.

4. After a further period of interaction will be located in the Local Information-Participation box.

5. After a period of time will be located in the Local Information-Autonomy box.

\subsubsection{Organizational and institutional level of analysis}

We now extend our methods to the organizational level. The materials here are a reformulation and clarification of our views and evidence expressed in the previous paper (Purdy and Gago, in press).

The main theoretical basis here is the psychology of personal constructs which considers each individual as unique (Kelly, 1955). Although unique, people do not operate in isolation. The name of the psychology, personal construct psychology, highlights the psychology's emphasis on what people do and construe in all spheres of life. Although we construe uniquely, classifications have been made with the personal constructs of managers. In a study of senior managers on one committee in a UK Regional Health Authority, when they construed the financial management accounting data provided to and used by that committee, patterns of personal financial management accounting constructs emerged. These classifications of such personal constructs demonstrates a commonality or similarity of views amongst the managers in one organization (Purdy, 1991).

It is possible to consider one organization from the personal construct perspective because the psychology includes, amongst other things, the notion of sociality. A sociality of views occurs when one person understands the social processes of the other person. Here the social processes of the other person are involved in the organization in which they work. It is clearly quite valid to seek and accept the views of a person about the position of an organization in which they work. It was anticipated that there could be different organizational views about an organization's position, depending upon which individuals are involved and their specific views.

The Information-Influence Matrix was formed from the social construction literature. The socially constructed reports and accounts of some companies, newly floated on the London Stock Exchange, were used as empirical evidence of each company's 
stated use of accounting data with each company's employees. Through the use of the constructions of five Information markers and five Influence markers associated with an Information-Influence Matrix (as mentioned above), it was possible to demonstrate the differences in Information and Influence for the employees of each company. The differences amongst each company's types of accounting data and forms of organizational influence, reported as available to employees, enabled the companies to be considered in one of three different areas of an Information-Influence Matrix (Purdy, 1993b).

The outcomes of the activities and the outcomes we anticipate observing will be socially constructed. The socially constructed reports were used with an Information-Influence Matrix, and in the same way the socially constructed outcomes of the Galician Health Centres, in relation to changes in Galician healthcare, can be represented by an Information-Influence Matrix. This is our theoretical basis for analysing organizational activities.

2.2.7.1. A Health Centre's Organizational Information-Influence Matrix. The same five markers of Information and of Influence will be used with the organization as have been used with the managers in the previous two subsections. This brings with it the same notions that are known and have been anticipated and those that have not.

Our understanding of the Galician legislation, with its written policy towards each Health Centre Organization, is that each Health Centre has the original position of No Information and No Influence. When the new system starts it will provide Local Information in a Communication position, but the intention is to pass through Consultation and Participation and to move to an Autonomy influence position with Local Information.

The anticipated movements of these changes for a Health Centre Organization on a Health Centre Matrix are shown in Fig. 5.

\begin{tabular}{|c|c|c|c|c|c|}
\hline \multirow[b]{2}{*}{ Information } & \multicolumn{5}{|c|}{ Influence } \\
\hline & No influence & Communication & Consultation & Participation & Autonomy \\
\hline \multicolumn{6}{|l|}{$\begin{array}{l}\text { Distant } \\
\text { Information }\end{array}$} \\
\hline \multicolumn{6}{|l|}{$\begin{array}{l}\text { Medium } \\
\text { Information }\end{array}$} \\
\hline Local Information & & $\begin{array}{l}\text { 2. Organization } \\
\text { new system } \\
\text { starts here }\end{array}$ & $\begin{array}{l}\text { Organization } \\
\text { moves through } \\
\text { here }\end{array}$ & $\begin{array}{l}\text { Organization } \\
\text { moves through } \\
\text { here }\end{array}$ & $\begin{array}{l}\text { Organization } \\
\text { changes } \\
\text { complete for } \\
\text { Autonomy }\end{array}$ \\
\hline No information & $\begin{array}{l}\text { 1. Originally } \\
\text { Organization } \\
\text { here }\end{array}$ & & & & \\
\hline
\end{tabular}

Fig. 5. Theoretical/anticipated changes of a Health Centre Organization on a Matrix. 
2.2.7.2. Health Centres Framework of Issues. The Framework of Organization Issues and the changes anticipated for the Health Centres are:

1. Original position is No Information-No Influence.

2. New system starts in the Local Information-Communication box.

3. After a period will be located in the Local Information-Consultation box.

4. After a further period will be located in the Local Information-Participation box.

5. After a period of time will be located in the Local Information-Autonomy box.

\section{Field studies}

\subsection{Background}

\subsubsection{Relationship of theory and objectives of field studies}

The theoretical perspectives section set out three different areas in need of empirical evidence:

1. At the level of the Health Centres we anticipated that if a Health Centre followed the reforms then it would move from an original situation of No Information and No Influence and with the start of a new system it would move to the position of Local Information/Communication to Local Information/Autonomy. This was set out in a Framework of Five Organization Issues and the changes anticipated for the Health Centres on a Health Centre Organization Matrix. We required empirical evidence about the events occurring at the various Health Centres in the process of reforms, in order to verify or modify or negate our theoretical Framework of Five Issues and the movement on a Health Centres Organization's Matrix. Our objective was to obtain evidence from a Financial Manager about these events along with any appropriate materials from Health Centre Managers.

2. We anticipated that if a Financial Manager followed the reforms then he would move from a position of Local Information/Autonomy to being a recipient of Different Local Information/Communication. This was set out in a Framework of Five Issues on the personal Information-Influence Matrix of a Financial Manager. We required empirical evidence about a Financial Manager's actions, during the course of the reforms with a Health Centre Manager, in order to verify or modify or negate our theoretical Framework of Five Issues and the movement on a Financial Manager's Matrix. Our objective was to obtain evidence from a Financial Manager about these events.

3. In a similar manner we anticipated that if a Health Centre Manager followed the reforms then he would move from a position of No Information/No Influence to Local Information/Autonomy. This was set out in a Framework of Five Issues on the personal Information-Influence Matrix of a Health Centre Manager. We required empirical evidence about a Health Centre Manager's actions, during the course of the reforms with a Financial Manager, in order to verify or modify or negate our theoretical Framework of Five Issues and the movement on a Health Centre Manager's Matrix. Our objective was to obtain evidence from Health Centre Managers about these events. 
In each of these three areas we anticipated being able to consider the unfolding of events and to compare these with our Frameworks of Issues and Matrices then comment upon the differences.

\subsubsection{Background to access}

In order to conduct a study, in 1999, we made contact with the Galician Health Service, and, later that year were given permission to work with one of the five Galician area Financial Managers and a number, of Health Centre Co-ordinators who worked with this Financial Manager. The Health Centre Co-ordinators, who had the same function that we had attributed to the Health Centre Managers in the theory section of this paper, were to be contacted by us, after they had agreed to speak with us through the Financial Manager. We assured the Financial Manager that no information would be published that could identify anyone we spoke with, so as to allow all to speak with complete freedom.

The Financial Manager had regular contact with his Health Centre Co-ordinators, knew the stage of change that each Centre had reached and it was agreed that we would be allowed access to a number of different Health Centre Co-ordinators, the precise number and which co-ordinators were to be determined by the events of the adoption of reforms at Health Centres. We had no precise numbers in mind, since the Financial Manager indicated that there would be many Health Centres involved and a lot of opportunity for us to hold conversations with co-ordinators at various stages during the reforms.

\subsubsection{Methodology with Financial Manager, access, protocols between authors and participants}

The collection of empirical evidence started when both authors undertook an extensive conversation with the Financial Manager, in both Spanish and English lasting 2 hours. The methodology for the meeting followed the open conversational approach towards the manager, being attentive and listening to his thoughts, responding to these with appropriate questions being centred on the person and, making appropriate notes, as used in a previous study with managers (Purdy, 1993a, 1993b). On this occasion, however, the Financial Manager was content for a tape recorder to be used too.

This conversation obtained details of the Financial Manager's job and the Galician Health Service's Health Centre Organization, existing structure, its current systems of doing things, the expenditures of previous years and the budget. He spoke about the change experienced and to be experienced by the Galician Healthcare Service and the new system in terms of influence exercised and the use of accounting information. Motivation and incentives related to the new system were also discussed. We call the former the old system and the latter the new system.

At this conversation it was agreed that at appropriate and convenient times the Financial Manager would allow one author to collect the views of a number of the Health Centre Coordinators and himself. In this way the progress of the Financial Manager and some Health Centre Co-ordinators would be noted as the new system was introduced. It was accepted that we had to follow the activity of the Financial Manager and could not approach anyone other than through him. No definite time horizon was placed on this work. The Financial Manager had a general expectation that he would try to bring about the planned alterations 
as quickly as was practicable and expected sound progress with a number of Health Centres within 3-4 years.

In the period between September 1999 and December 2001 contact was maintained with the Financial Manager with a number of phone calls, when written notes were made, and emails. This contact allowed the collection of additional materials and the legal references regarding the new system and its implementation. During this time the Financial Manager allowed contact to be made with only one Health Centre Co-ordinator and thus only one conversation/interview was held with a Health Centre Co-ordinator.

At the final conversation with the Financial Manager, in December 2001, the open methodology was used, hand-written notes were taken but no tape recorder used. The Financial Manager was not provided with material related to the content of the interview beforehand. He spoke about the current situation of the new system and made general comments regarding the changes experienced by him in terms of influence and information from 1999 to 2001.

At this point our contact with the manager ended as he did not want to provide us with further detailed materials. He did subsequently comment on an early draft of this paper and the previous theoretical paper (Purdy and Gago, in press).

\subsubsection{Protocols between the authors}

During this conversation the authors were made aware that various parts of Galician legislation had forecast and indicated facets of the new approach being applied by the Financial Manager. The authors had already set down the general Framework and methods (Purdy and Gago, 2003), but did not know the precise nature of this existing legislation. This meant that a second theory paper might be required taking the legislation into consideration.

The authors wanted to produce the most accurate Frameworks and Matrices they could, after a translation of the laws into English and after a consideration of how these laws affected their previous theoretical position. They decided to work separately with one author working on the field studies. The separate working was an attempt to preserve the interpretation of the prospects of the law from being affected by practice, even inadvertently.

The other author amended the theory of the Frameworks and Matrices to incorporate the legal position, but retaining the views and anticipations held before we had contact with the Financial Manager. This interpretation from the law was produced, discussed and agreed with the second author. Before the theoretical parts of this work had been completed (Purdy and Gago, in press), only the second author knew what was happening in the field studies, and that remained the situation until 2 years after the field studies had in fact ended.

\subsubsection{Methodology with Health Centre Co-ordinators, access and protocols}

Our approach with the Health Centre Co-ordinators was similar to the Financial Manager for they would be assured that no information would be published that could identify anyone we spoke with, allowing them to speak with complete freedom. All notes of the conversation would be handwritten. It was also anticipated that they would have different backgrounds to the Financial Manager, likely to be medical practitioners not versed in our world, nor us versed in their medical worlds.

We considered the matters we wanted an interview to cover and produced a schedule of 33 questions, but, our intention was to encourage a free conversation from the Co-ordinator 
in as many cases as possible. The questions were based on previous research (Purdy and Gago, 2002). They were not expressed in academic jargon, but aimed at establishing general topics to be discussed, to stimulate further discussion with the co-ordinators and enable them to talk freely about their circumstances and their matters of concern. They would not be provided with a copy of the questions.

Our intention had been to speak with a sufficient number of co-ordinator who were at different points in the new system. We wanted to follow their changes to the management of a Health Centre. The purpose of the interaction would be to find out as much as possible about any changes that had been envisaged, discussed, accepted, rejected, and the effects of the actual situation on the Centre and the co-ordinator. Despite our best attempts to interview more, only one Health Centre Co-ordinator was interviewed.

During the course of the sole interview, the co-ordinator was asked about his job and its evolution since he had started at the Health Centre. He was also asked about his influence on decision-making in the Health Centre and the accounting data available for it. Details about the accounting system and the use of accounting data by him and his subordinates were written down. His training, motivation and incentives were also mentioned.

\subsection{Data collected from Financial Manager-September 1999}

\subsubsection{Structure}

The Financial Manager's views in this section have been categorised into three sets of views. First, his Background, second the Factual Changes comprised of Old Structure and System, the Determination of the New System for Health Centres, the New System, Budgets and Data Use in a Health Centre and finally Participation, Performance and Responsibility.

The third set of views is the Financial Manager's personal observations about the changes. He commented on the source of the New System, Perceptions about the New System, Management and the New System, finally Initial Anticipations about the New System.

3.2.1.1. Financial Manager's background. The manager was a Divisional Financial Manager working in Economic Resources with a degree in economics, 10 years training and wide experience in accounting and finance. He valued most his independence in decisionmaking in his work. He valued most in a subordinate the ability to give possible solutions to the diverse problems that might appear in a Health Centre. He valued most in a superior the ability to listen and involve all the personnel in a common goal.

\subsubsection{Factual changes.}

3.2.1.2.1. Old structure and system. In 1999, the Galician Health Service was managed through five divisions: Human Resources, Pharmacy, Public Health, Healthcare and Economic Resources. Throughout the Region there were a number of public hospitals, and about 500 primary Health Centres (subsequently called Health Centres). Each centre was administered locally by a co-ordinator but managed financially by one of a small number of senior divisional managers such as this Financial Manager.

The Financial Manager worked with the Director of Healthcare, the person responsible for the deployment of doctors, nurses and care in the Galician Region. Within this relationship, the Financial Manager discussed the care concerns of the Health Centres. 
The Financial Manager also worked with the Economic Resources Director, the person responsible for the financing of healthcare services in the Galician Region. The Economic Resources Director was also responsible for a range of associated activities such as the general administration of the accounting systems, the provision of supplies, maintenance and personnel to the hospitals and the Health Centres. For each Health Centre the Financial Manager sought to co-ordinate the provision of healthcare along with all of these associated activities.

The total amount of finance for all health care was fixed for the Galician Region. The Financial Manager brought together the current healthcare activity at each Health Centre and the finance for this. He sought approval for various levels of activities at each Health Centre from the Director of Healthcare, and determined the budget for these centres with the Economic Resources Director. Occasionally, during the meetings to determine the budget, some of the proposed activities were dropped because there was a limit on the amount of finance available for the following year. There was a true negotiation of alternatives, and at times this had been at the national level.

To construct a budget the managers in Economic Resources took the total of the previous year's expenditure, added the anticipated activity and discussed this in different meetings until that budget was approved. There was one large budget for all Health Centres kept at the division. The budget was nominally allocated to each Health Centre but there were no transfers of funds to the Health Centre because the finance was held at the division. Records of activities and spending were kept at the division by the Healthcare Division and the accounting system in the Economic Resources Division.

Normally there was someone responsible for a centre, a voluntary position filled normally by a medical doctor. The authorisation for any activity had to be agreed by the Financial Manager. Even small repairs and the purchase of any small items were required to be taken from a budget that had been previously agreed before the expenditure. In this way the Financial Manager noted that he has "close control for if I did not control them they would go crazy and spend".

3.2.1.2.2. The determination of new system for the Health Centres. Health centres that wanted to work with the new system had been determined by approaching the each centre's medical staff and getting their agreement. The staff were told that the new system would be computerised and allow them to improve their service, providing more time for patients. Their participation in this new system was wanted. In theory all staff at a Health Centre could be involved in the decision to change, however, in practice the decision had to be made by common agreement of all the professional staff, the doctors, nurses and administrators.

It was essential that the professionals had an interest in participating in the new system, because the small additional financial incentive was unlikely to have much effect upon them. For example, doctors could earn more in private medicine. If the professionals did not want to change, then the Health Centre would continue with the old system, for the time being. There were 45 centres working with the old system and 32 working with the new system. The new system was being implemented gradually in those Health Centres that had expressed an interest in working with it.

3.2.1.2.3. New system. There were a variety of objectives with the new system which started to operate in the administrative year January 1997. An objective of the new system was for each Health Centre to create a healthcare management system with its professionals' 
preferred activities for the Health Centre. In addition, therefore, to a Health Centre's current healthcare activities, its professionals could state what other matters they would like to undertake. They could produce a programme of oral hygiene, or produce a history of its population's health. These additional activities needed to be planned and financed separately to ensure that current healthcare was maintained and unaffected.

Another objective of the new system was to enable appropriate Health Centres to move in the direction of more autonomy. For the first time there would be a recognised Health Centre Co-ordinator, a doctor responsible for what happened there. The Financial Manager described a co-ordinator as, "our intermediary amongst other professionals who tells us all of the problems of everyone in the centre".

A co-ordinator organised all of a centre's work, from healthcare service provision to the replacement of personnel. The co-ordinator could buy small quantities of supplies and small repairs without previous authorisation. However, the Financial Manager always required the co-ordinator to agree a budget with him before buying, even if only with a telephone call. This was because the Financial Manager liked to control them permanently.

In the new system, the centre co-ordinator participated in formulating an agreement (it was not a contract) about the anticipated activities and their financing with the Financial Manager. The agreement was reached by consensus. Health centre activities were discussed and the associated budget was drawn up. There was a concern for both the quantity and quality of work at a centre. The co-ordinator was expected to be at a centre 7 hours a day.

3.2.1.2.4. Budgets and data use in a Health Centre. Each centre had its own budget which was related to the anticipated activity for the next year and known to the co-ordinator. The budget preparation started with the current year's activities and the amount expended. The budget had two basic components, personnel expenditure and other expenses for running the centre.

The estimates of running expenses included the associated medical and nursing materials, electricity, heating and cleaning. This approach gave the Financial Manager and the coordinator the opportunity for closer control of the centre's activities, since they both knew the budget. The money and the budget were still held at the division.

In September 1999, the new system had two levels of co-ordination operating. There were 30 centres at the first level whose co-ordinator had to send expenses information and invoices to the Financial Manager for payment. With this level the co-ordinator received summaries of the resources used. There were two centres at the second level whose coordinator received the Level 1 information but also received details of personnel capacity for the centre and the amount of budget still available. Table 1 shows the total numbers and different levels of Health Centre Co-ordinators at September 1999.

Table 1

Total numbers at different levels Health Centres/managers

\begin{tabular}{lc}
\hline Levels & 1998 \\
\hline No level & 45 \\
Level 1 & 30 \\
Level 2 & 2 \\
Total & 77 \\
\hline
\end{tabular}


The Health Centres did not keep accounting records. From 1997, the co-ordinators were provided with detailed information about the financial position with sheets of data about the previous month. The data was prepared in a way that could be understood by those individuals who were not used to accounting data. The sheets contained all of the data about bills passed for payment, and all of the items from the central stores. The reason for this regular reporting was to enable the Health Centre to affect its usage, and to correct any activities so that the budget was not exceeded. This system changed in October 1998 to three monthly reporting of information from the Finance Department. A co-ordinator at any level received three monthly data sheets and could now examine the centre's evolution of activities.

The Financial Manager wanted to send data, especially budget associated data, to the Health Centres because he considered that the co-ordinator should have comprehensive information, and be able to work with the budgets. When the financial data was provided to the Health Centre Co-ordinators, a dialogue started with the Financial Manager about what the data meant, and what it could be used for.

3.2.1.2.5. Participation, performance and responsibility. By moving to the new system it was possible for a centre's staff to have some degree of participation in the formulation of that centre's agreement with the Financial Manager. The Financial Manager observed that all staff had seen the agreement and "were able to participate in an active way. The staff decided upon the service they would provide, what they would do and how they would do it."

Within all agreements, the Health Centre staff were allowed to employ new staff, under guidance, whilst other activities were their responsibility. At the second level the staff were asked to achieve a minimum amount of activities over the year. If this minimum was achieved the staff received a salary bonus, paid 3 months after the year's end.

The co-ordinator were professional people who needed to be involved, and not treated as though they were under suspicion and constant vigilance. The involvement of the professionals had been encouraged by offering them the prospect of more money.

In the new system the doctors' salaries were variable, and varied as a function of the objectives achieved. The salary issue was not negotiable, because it was an objective of the new system for the doctors to have a variable salary, not a fixed one. The results of each Health Centre were measured using the objectives and programme agreed. At Level 2 the Health Centres could generate savings in relation to the budget and then decide how to use a part of those savings.

\subsubsection{Financial Manager's personal observations-September 1999.}

3.2.1.3.1. Source of new system. The system had come from central government and the Financial Manager was very enthusiastic about the system for it was an opportunity to improve the delivery of healthcare and resource allocation. The notions of productivity included with the programme also came from central government.

3.2.1.3.2. Perceptions about the new system. An agreement made at the first level was only a joint agreement about information. The Financial Manager anticipated that more Health Centres would join Level 1 within the next year.

The staff working at Level 2 were uncertain about the savings they would receive. The doctors at Level 2 liked the power to decide where and how to use the money, but did not 
like the inability to modify the budget headings and so were unable to use funds in the ways they thought appropriate.

The Financial Manager liked the direct participation of the co-ordinators in determining the expenditures, as they were actively participating in running the Health Centre and improved the new system daily. The Financial Manager did not like the rigid norms imposed by the new system and the lack of freedom to act.

3.2.1.3.3. Management and the new system. There had been only slight improvements in the management of the Health Centres at Level 1 with the new system. The co-ordinators had received information, but could not alter affairs much. Level 1 made the co-ordinator aware of the expenditure of the centre's activities, and how the budget was allocated to various expenditures.

The two Level 2 Health Centres now had monetary incentives which were important, but the most valued incentive for doctors was their independence in management. They could now act as professionals. The divisional senior management considered that a fixed salary would not act as an incentive for the doctors. In one of the only two Level 2 Health Centres, a saving on the budget had occurred, whilst in the other there had been an increase in expenditure which had now stopped.

The health professionals now knew what their actions meant for expenditures. Their activities caused the expenditures which they now felt they owned and had become more interested in expenditures.

3.2.1.3.4. Initial anticipations about the new system. There would be a more fluid relationship in which everyone would work together to achieve the objectives. In future the relationship of the Health Centre with the Financial Manager would be different and it would not be limited to the Health Centre being in contact, informing the Financial Manager when something was wrong.

The management of healthcare was anticipated to improve because the professionals were involved and would see that their actions had been useful.

\subsection{Data collected from Financial Manager-from September 1999 to December 2001}

\subsubsection{Introduction}

It was noted earlier that, as anticipated, two face-to-face conversations were held with the Financial Manager. As noted at 3.1.3, contact was maintained by emails and telephone conversations to collect legal details and additional materials. After these had been received contact continued and the Financial Manager had been encouraged to allow access to more than one co-ordinator. At the final conversation he provided the latest figures about the changes with the Health Centres at December 2001. The materials in sub-section 3.3 come from these emails and all other conversations.

\subsubsection{New system-Levels $2-4$}

By the end of the study the Financial Manager had discussed these new Levels 3 and 4, and, introduced a Level 3 Health Centre. He noted the main difference between Level 2 and Level 3 status was that a co-ordinator at Level 2 could decide only how to spend a part of the budget savings, whilst the Level 3 co-ordinator could had increased influence and could decide how to spend a larger part of the budget savings. 
The Financial Manager had also investigated the possibilities of a Health Centre moving to proposed self-management of Level 4. With self-management the Financial Manager considered a co-ordinator to be able to be in position of autonomy, an ideal state that would be Utopia. He noted, however, that with the current Spanish laws and healthcare norms it was impossible for the Galician Region to create a Level 4 Health Centre. He felt very frustrated because the system had failed to be able to bring about change.

He noted that the centres at Levels 2 and 3 had internal organizational structures, which implied that those at Level 1 did not. This might mean that those centres at Level 1 and those centres in the old system are the same in terms of organizational structure.

\subsubsection{Budget use and budget performance}

Every 3 months the Financial Manager met with each co-ordinator to discuss how the centre's actual activities compared with the anticipated activities. The Financial Manager noted that the Health Centre Co-ordinators at both Level 2 and 3 gave reasons to justify why their expenses had increased. The Financial Manager only occasionally accepted their reasons and generally did not. The use of any saving on the budget was negotiated. Previously, Health Centre Co-ordinators had been free to decide the use of savings; however, the Financial Manager had observed that substitutions of medical staff were the only use chosen, and because of that sole use he then imposed some limits on the use of budget savings.

There was a legal reason why the centre should not devote this budget saving to staff substitutes. The budget was a public matter regulated by Spanish law into particular budget headings which made it very difficult to move funds across budget headings. The Health Centre Co-ordinators and the Financial Manager usually agreed to devote over 33\% of the saving for substitutions, $33 \%$ in training and the rest was decided by the co-ordinator. The Financial Manager established these percentages based upon historical information. The Regional Financial Department also was more flexible in allowing more variations from the anticipated expenses.

\subsubsection{Low salaries and lack of interest in the new system}

The Financial Manager observed that that the voluntary new system was not attractive because the Health Centre personnel had high salaries with a comparatively small addition for making it a managerial job. (This was confirmed by Anton, the co-ordinator interviewed.) The Financial Manager observed that the co-ordinator, Anton, had left the healthcare system for health reasons. The Financial Manager considered that the incentive of having an extra amount of money, free for using in the Health Centre, should have acted as a bigger incentive than it had been.

\subsubsection{Less Health Centres in the new system than at the start of the study}

This study began in September 1999 and change since, in December 2001, was that there were less individuals and Health Centres involved in changes than in 1999.

At December 2001, there were 66 Health Centres at no level, 10 centres at Level 1, 1 at Level 2 and 1 at Level 3. This meant that the Financial Manager had moved to Level 3 with 1 Health Centre, Level 2 with 1 Health Centre, Level 1 with 10 Health Centres and had 66 Health Centres at no level. These situations of 1998 and 2001 are in Table 2. 
Table 2

Total numbers at different levels Health Centres/managers

\begin{tabular}{lcc}
\hline Levels & 1998 & 2001 \\
\hline No level & 45 & 66 \\
Level 1 & 30 & 10 \\
Level 2 & 2 & 1 \\
Level 3 & - & 1 \\
Total & 77 & 78 \\
\hline
\end{tabular}

3.3.6. Movements relating to adoption of the new system with individual co-ordinators and Health Centres during the study

During the course of this study there had been movements of the Health Centre Co-ordinators in relation to the adoption of the new system and accordingly the Health Centres. From September 1999 until December 2001 the pathways followed were:

1. Old system-Level 1 (1999) to Level 2 to Level 3 (2001): one Health Centre Manager.

2. Old system-Level 1 to Level 2 (1999, 2001): one Health Centre Manager.

3. Old system-Level 1 to Level 2 (1999) to old system (2001): one Health Centre Manager that we interviewed left the system because of health reasons.

4. Old system-Level 1 (1999, 2001): 10 Health Centre Managers.

5. Old system-Level 1 (1999) to old system (2001): 19 Health Centre Managers.

6. Old system (1999, 2001): 45 Health Centre Managers.

7. Old system: one new Health Centre into the system.

\subsection{Data collected from interview with Health Centre Co-ordinator-July 2000}

\subsubsection{Background}

A schedule of questions was prepared, but the intention was to encourage a free conversation in as many cases as possible. Essentially, Anton responded to these questions at a meeting in July 2000. Anton was a doctor who had been in the Health Centre for 12 years and had acted as co-ordinator since the introduction of co-ordinator, 9 years previously. On becoming co-ordinator he received a small additional salary.

His principal functions as co-ordinator were: (1) to be a link between the senior managerial level and the Health Centre colleagues, (2) to manage the different types of healthcare-emergencies, prevention and promotion of health, (3) to be leader of colleagues and a representative between the senior managers and the Health Centre administration.

The major change in the 9 years had been the system of nursing, which had improved the running of the centre.

\subsubsection{Activities and organization}

The Health Centre was at the second level of change as it had agreed to move to Level 2, 1 year before. There was not much difference between Level 1 and the recently introduced Level 2. Level 2 had not affected the majority of people in the centre and had not yet really 
become real for them. The majority of personnel were temporary so it was difficult for them to appreciate something that did not directly affect them.

Anton noted the centre offered a programme of healthcare including emergencies, dental clinic, opthalmics, paediatrics, rehabilitation, maternity, social assistance and shortly pharmacy. The centre was organised in a way which was similar to the running of other Health Centres with its work of consultations and clinics. There were various meetings with colleagues in different groups depending upon the matter.

The centre had an annual agreement with the Financial Manager about the anticipated activities of the centre and the financing of these. Anton had participated in the change process since its introduction. The process started with a budget based on the previous year's expenditures of the various activities. A specific problem had occurred with substitute personnel. In summer the population increased with tourists, so the centre needed more people than normal because some personnel were on holiday. Anton had negotiated this and more personnel and money had been achieved.

Anton was asked if he had much influence on the content of the activities and/or the finance of the current agreement. He noted occasionally he had not agreed with the budget, so he negotiated until there was a compromise, the issue of the substitute personnel was an example. Generally with other items, he did not know why one area of expenditure suddenly increased. There were too many factors which affected these expenditures, and with disposable materials he did not understand why expenditures in the clinic had increased so much. Perhaps the emergencies had caused the increase, there was a long way to go for him to understand these things. He could not influence these matters.

\subsubsection{Accounting data}

Every 3 months, monthly amounts of accounting data about each item in the budget came from the Regional Management. The accounting data came from the Regional Financial Accounting systems, but it was not explained. Anton had discussed appropriate parts of this data in meetings with those in the areas involved. Anton thought the data was acceptable, a valid system and had nothing negative to observe about it. Anton considered he understood the data provided and could use it, but at times he had to have it explained. He did not know the language of the budgets that the Regional Managers understood but then phoned them for explanations.

The budget had been, and currently was, an amount of money to spend. There had been a few changes in the way money had been allocated for planned activities. He thought that the centre wanted to move to the idea that the budget related to the centre's activities, because the centre had its own ideas.

\section{Analyses of findings}

This section analyses the findings from the interactions with the Financial Manager for the organization analysis in the first subsection, and his views about his job and his views about Health Centre Co-ordinators in the second subsection. The third subsection uses materials from the interview with the Health Centre Co-ordinator. The section compares 
the findings with the theory for organizations in Section 2.2.7, for the Financial Manager in Section 2.2.5 and the Health Centre Co-ordinator in Section 2.2.6.

\subsection{Organization analysis of Health Centres}

\subsubsection{Before 1997-old system}

The changes to the old system began in January 1997 before the study started. Prior to January 1997 there were Health Centre Co-ordinators who were volunteers. The Financial Manager indicated that these were not allowed to exercise any influence in the organization in the formal sense. The individuals in the Health Centres appeared to be in a position of No Influence. They also did not receive any information from the accounting system. They were in a position of No Information.

The Financial Manager had a wide range of influence over the funds that the Health Centres used. They were financed with a fixed amount, based upon the centre's previous activity, and a variable amount, based upon the financing of the agreed amount of additional activity with the senior Regional Managers. These senior managers discussed matters until a budget was approved.

In these ways the Financial Manager (along with other Regional Managers) participated in the setting of the activities and budgets for these Health Centres. The budget was allocated in a fictitious way amongst all the services inside the area, including the Health Centres.

The Financial Manager was in a position of Total Influence in financial matters from the perspective of the Health Centre. The Health Centres never received funds physically. The Financial Manager had access to all of the accounting information about the centres. $\mathrm{He}$ had Total Information.

The situation with the 77 Health Centres and the Financial Manager is represented in the Health Centres Matrix of Information-Influence relating to the Health Centres with the old system and shown in Fig. 6. The theoretical situation of Total Information and Total Influence was not explicitly dealt with for this field study. It has occurred and we have used our Information-Influence Matrix approach to demonstrate its existence and position on an extended Galician Information-Influence Matrix.

\begin{tabular}{|l|l|l|l|l|l|l|}
\hline \multirow{2}{*}{$\begin{array}{l}\text { Accounting } \\
\text { Information }\end{array}$} & \multicolumn{5}{|c|}{ Influence } \\
\cline { 2 - 7 } & No Influence & Communication & Consultation & Participation & $\begin{array}{l}\text { Sole Participation/ } \\
\text { Autonomy }\end{array}$ & $\begin{array}{l}\text { Total } \\
\text { Influence }\end{array}$ \\
\hline Total Information & & & & & & $\begin{array}{l}\text { Financial } \\
\text { Manager }\end{array}$ \\
\hline $\begin{array}{l}\text { Distant } \\
\text { Information }\end{array}$ & & & & & & \\
\hline $\begin{array}{l}\text { Medium } \\
\text { Information }\end{array}$ & & & & & & \\
\hline $\begin{array}{l}\text { Local } \\
\text { Information }\end{array}$ & & & & & & \\
\hline No Information & $\begin{array}{l}77 \text { Health } \\
\text { Centres }\end{array}$ & & & & & \\
\hline
\end{tabular}

Fig. 6. Information-Influence positions in the Health Centres and the Financial Manager old system before 1997 Matrix. 


\subsubsection{From January 1997-new system begins}

The new system started in 1997 and required a person, usually a doctor, to be responsible for a Health Centre. He had to be in the Health Centre for at least 7 hours a day, to have enough time to perform his new job, as well as his medical tasks.

The Health Centre Co-ordinator, was the intermediary between the Financial Manager and the other individuals in the Health Centre. The Health Centre Co-ordinator informed the Financial Manager of any problems that occurred. He was also responsible for organising the activity in the centre, such as substitutions.

The participation of a Health Centre in the new system was voluntary. In order to attract centres to adopt the new form and to get individuals to become co-ordinator, those who participated were rewarded with additional administrative resources (staff for administrative tasks, computers, phone, etc.). Such resources let the doctors have more time for their medical work. The Health Centre Co-ordinators also received a small addition to their salary which was variable. The additional salary took into consideration the quantity and the quality of the work. Further motivation was provided by the fact that the co-ordinator knew the amount the centre was spending.

\subsubsection{September 1999-our first conversation}

The new systems for Health Centres involved three levels of possible change for these and the co-ordinators. At Level 1 the co-ordinator receives the three monthly statements of expenditures and inventory movements, all decisions are made by the Financial Manager. Level 2 the co-ordinator receives the three monthly statements of expenditures and inventory movements, has some influence over the appointment of personnel in the Health Centre and tries to control expenses. The co-ordinator also has some influence on how the centre will use a part of the 'savings' on these expenditures, compared with the budget. Level 3 has the same information received as Level 2, but the co-ordinator has more influence and a larger amount of 'savings' on the budget to spend.

We spoke with the Financial Manager in September 1999 when he had negotiated with 30 centres to take up an agreement to work with Level 1 and with two centres to work at Level 2. The agreement was discussed within each centre and signed by the centre and the region. The agreement was voluntary, a Health Centre could take part at any level it wished, and move up or down from this. These 77 organizations are in Fig. 7 and demonstrate the Information-Influence Matrix position for Health Centres and the Financial Manager at September 1999. Although the changes are underway the ultimate responsibility for all 77 centres stays with the Financial Manager.

Forty-five Health Centres were not involved in the new system and are shown in the old system position of No Information-No Influence. The 30 Health Centre Managers at Level 1 received accounting data regarding their monthly expenditures every 3 months, and data about expenses and their inventory movements. The Financial Manager prepared that information in a way that could be understood by individuals not used to accounting data. The aim was that the Health Centre Co-ordinators knew their expenses, making the co-ordinator conscious of these. In this way their Health Centres moved from No Information to Local Information. In terms of influence, the Financial Manager communicated the decisions that affected the centre to the Health Centre Co-ordinators. Thus, they moved from No Influence to Communication. 


\begin{tabular}{|c|c|c|c|c|c|c|}
\hline \multirow[b]{2}{*}{$\begin{array}{l}\text { Accounting } \\
\text { Information }\end{array}$} & \multicolumn{6}{|c|}{ Influence } \\
\hline & $\begin{array}{l}\text { No } \\
\text { Influence }\end{array}$ & Communication & Consultation & Participation & $\begin{array}{l}\text { Sole Participation/ } \\
\text { Autonomy }\end{array}$ & $\begin{array}{l}\text { Total } \\
\text { Influence }\end{array}$ \\
\hline $\begin{array}{l}\text { Total } \\
\text { Information }\end{array}$ & & $\begin{array}{l}\text { Financial } \\
\text { Manager } \\
\text { Level } 1\end{array}$ & $\begin{array}{l}\text { Financial Manager } \\
\text { Level } 2\end{array}$ & & & $\begin{array}{l}\text { Financial } \\
\text { Manager }\end{array}$ \\
\hline $\begin{array}{l}\text { Distant } \\
\text { Information }\end{array}$ & & & & & & \\
\hline $\begin{array}{l}\text { Medium } \\
\text { Information }\end{array}$ & & & & & & \\
\hline $\begin{array}{l}\text { Local } \\
\text { Information }\end{array}$ & & $\begin{array}{l}30 \text { Health } \\
\text { Centres } \\
\text { Level } 1\end{array}$ & $\begin{array}{l}2 \text { Health Centres } \\
\text { Level } 2\end{array}$ & & & \\
\hline No Information & $\begin{array}{l}45 \text { Health } \\
\text { Centres } \\
\text { Old } \\
\text { System }\end{array}$ & & & & & \\
\hline
\end{tabular}

Fig. 7. Information-Influence positions in the Health Centres and the Financial Manager in September 1999 Matrix.

In Health Centres at Level 2, the Health Centre Co-ordinators could exert some influence on the daily small running expenditures of the centre. After the co-ordinator produced a budget, it was authorised by the Financial Manager, or not. With a very few decisions, the Health Centre Co-ordinator moved from No Influence to Participation. However, in most of the decisions he was in Consultation with the Financial Manager.

The Financial Manager provided the Health Centre Co-ordinators at Level 2 with the same information as those at Level 1 . However, Level 2 Health Centre Co-ordinators gained access to medium information during the discussion process and so had Local Information and Medium Information.

We have used a Health Centre Organization Matrix to show the position the position at September 1999 by using the enlarged Matrix of Fig. 6. The changes found are consistent with changes processes anticipated before the study.

\subsubsection{December 2001-our last conversation}

By December 2001 the Financial Manager had dealt with the new system at Level 3 with more influence on spending budget savings than at Level 2. It was known that the Level 4, the self-management level, a position of Autonomy or Sole Participation, was currently impossible to attain. There were less Health Centres involved with the new systems than in September 1999.

The Financial Manager had moved to Level 3 with one Health Centre, where its coordinator had moved closer to Participation than he was at Level 2. The information had not changed from Level 2. The one Health Centre that remained at Level 2 had slightly less influence but was still in the Consultation position. There were 10 Health Centres at Level 1 in the Communication position.

At this time, there were 66 Health Centres working with the old system. These positions are shown on the Information-Influence Matrix of the Health Centres and the Financial Manager in Fig. 8. 


\begin{tabular}{|c|c|c|c|c|c|c|}
\hline \multirow[b]{2}{*}{$\begin{array}{l}\text { Accounting } \\
\text { Information }\end{array}$} & \multicolumn{6}{|c|}{ Influence } \\
\hline & $\begin{array}{l}\text { No } \\
\text { Influence }\end{array}$ & Communication & Consultation & Participation & $\begin{array}{l}\text { Sole } \\
\text { Participation/ } \\
\text { Autonomy }\end{array}$ & $\begin{array}{l}\text { Total } \\
\text { Influence }\end{array}$ \\
\hline $\begin{array}{l}\text { Total } \\
\text { Information }\end{array}$ & & $\begin{array}{l}\text { Financial } \\
\text { Manager } \\
\text { Level } 1\end{array}$ & $\begin{array}{l}\text { Financial } \\
\text { Manager } \\
\text { Level } 2\end{array}$ & $\begin{array}{l}\text { Financial } \\
\text { Manager } \\
\text { Level } 3\end{array}$ & & $\begin{array}{l}\text { Financial } \\
\text { Manager }\end{array}$ \\
\hline $\begin{array}{l}\text { Distant } \\
\text { Information }\end{array}$ & & & & & & \\
\hline $\begin{array}{l}\text { Medium } \\
\text { Information }\end{array}$ & & & & & & \\
\hline $\begin{array}{l}\text { Local } \\
\text { Information }\end{array}$ & & $\begin{array}{l}\text { 10 Health } \\
\text { Centres } \\
\text { Level } 1\end{array}$ & $\begin{array}{l}1 \text { Health Centre } \\
\text { Level } 2\end{array}$ & $\begin{array}{l}1 \text { Health Centre } \\
\text { Level } 3\end{array}$ & & \\
\hline No Information & $\begin{array}{l}66 \text { Health } \\
\text { Centres } \\
\text { Old } \\
\text { System }\end{array}$ & & & & & \\
\hline
\end{tabular}

Fig. 8. Information-Influence positions in the Health Centres and the Financial Manager in December 2001 Matrix.

\subsubsection{Discussion concerning Health Centres}

In comparison to 1999, 20 co-ordinators at Level 1 had diminished their influence by moving to No Level, making 66 at the No Level and leaving 10 in the Communication position. The one who remained at Level 2 had slightly less influence but was still in the Consultation position. The co-ordinator at Level 3 had moved closer to Participation than he was at Level 2. The information had not changed for the levels.

The Level 4 was the self-management level. The co-ordinator would be in a position of Autonomy or Sole Participation. The Financial Manager considered that Level 4 was an ideal condition, however, it was currently not possible to attain Level 4 with the current laws and healthcare norms. The Financial Manager thought that for a Health Centre to attain Autonomy would be a utopia.

Overall the outcome of this Health Centre change programme does not appear to have occurred in the ways anticipated by the central Spanish government, the Galician legislation and the Financial Manager. We do not know the retos of the Financial Manager or any co-ordinator. The change programme started in 1997 when all Health Centres were with the old system at No Level, and apparently with no information and no influence. In September 1999, at the first interview, the Financial Manager noted 32 (out of 77) Health Centres were involved with the new system. There were 30 at Level 1 and two at Level 2. At the last interview in December 2001 there were 10 at Level 1, 1 at Level 2 and 1 at Level 3. The Galician legislation promoted the ideas of autonomy which would be Level 4, but with the current laws and healthcare norms it was impossible to attain. Thus the legislative sentiments about autonomy and the focus on Regional Autonomy in 
healthcare were not followed through with the appropriate conditions for this to occur at Level 4.

The general lack of suitable conditions available for an autonomous Health Centre to exist might be some of the reasons why progress towards the new system has reversed during the time of our study. In September 1999 there were 45 with the old system at no level and in December 2001 there were 66 (with one additional Health Centre) with the old system. Our materials suggest that Health Centres at Level 1 had no organizational structures and this indicates only the one at Level 2 and one at Level 3 had such structures from the new system.

Our findings indicate the Financial Manager had total information and total influence over the relevant decisions at Health Centres working with the old system and with the new system Level 1. This suggests that the Financial Manager's decision-making has ended in more or less the same situation that he was in before the proposed changes. He had this total influence and information in relation to 77 Health Centres before the changes in 1997 and 78 in Dec 2001. The position of the Financial Manager has apparently altered very little, irrespective of the number of Health Centres he had worked with and started towards the new system.

The Financial Manager enjoyed having this degree influence over affairs, however, if his retos had included the need to have most of the Health Centres at Level 2 within 3-4 years, then this has not occurred and therefore could have had unsettling implications for him.

There were, then, only two cases where a co-ordinator had a little influence at Level 2 and some more influence at Level 3. At Level 2 the co-ordinator received guidance about taking on new staff but was responsible for and influenced the personnel activities and took joint-decisions with the Financial Manager about any budget 'savings'. At Level 3 the co-ordinator had more freedom about the choice of personnel and a larger amount of any budget 'savings'. It was also found that the amount of discretion that the co-ordinator had at Levels 2 and 3 had been reduced by the end of the study because the Financial Manager noted that co-ordinator generally wanted to spend savings from the budget on medical staff substitutions. This could not continue easily because of the legal definitions of the budget headings and funds could not be transferred between these, they had to be used for designated purposes.

Since the co-ordinator we had interviewed had left for health reasons, we were unable to discuss matters with him a second time and acquire some further understandings of what had happened.

Without interviews with other co-ordinator, it is impossible for us to advance many reasons for the lack of Health Centres moving to new systems which might be associated with the relationship with the Financial Manager.

Irrespective of the lack of sustained change to the new system for Health Centres, it would appear that the realities of everyday life were different to those before 1997 for the Financial Manager. Then he had budgets for all Health Centres agreed only at the Regional Office, whereas with the proposed changes, after regional agreement there had been discussions with many Health Centres about the amount of their budget. In this way if his retos had been based upon the time spent on activities as opposed to outcomes then this could have occurred with more acceptable implications for him.

In relation to the budget savings it was noted that for a co-ordinator to achieve any budget savings the objective would be to keep the activity at a Health Centre to a minimum. This 
seems an unusual way in which to organise healthcare especially in view of the assertions of the Galician legislation about the benefits of these proposed changes.

It was found that the new system was implemented through a voluntary agreement with a Health Centre and that the Health Centre could vary this agreement to move up or down the new system levels or to the old system. The adoption of the new system would have led co-ordinators to receive a small additional salary and additional administrative resources to allow doctors more time for medical work. These might be retos for a co-ordinator, but have not been taken up by the majority. If we accept that medical staff could earn higher remuneration outside of a Health Centre through private practice, then the additional salary would be insufficient for the majority of medical staff to move towards becoming a co-ordinator.

When given a choice of usage of savings on the budget, the co-ordinator chose to substitute medical staff. This was not acceptable to the Financial Manager for legal reasons. However, the co-ordinators' choices/decisions may be indicative of need for a different retos or with other matters in Health Centres of which we are unaware.

It was noted that to raise the awareness of the Level 1 co-ordinator, the Financial Manager discussed the activities of a Health Centre and its financial implications with them. At this stage co-ordinators had no influence over decisions and such discussions could have caused the co-ordinators concern because they were unable to affect those expenditures. The Financial Manager noted that he generally rejected the reasons given by the co-ordinators to justify an increase in expenditures. These actions might be major reasons for the lack of changes.

The arrangements for information to the Level 1 co-ordinators were centred around accounting data about the last 3 months with expenses and stock movements. At Level 2 , co-ordinators influenced the daily small expenditures, but a budget had to be produced for each expenditure and authorised by the Financial Manager before it was incurred. This occurred because the Financial Manager would not allow the co-ordinators to spend without a budget, and even then, the budget application was not always approved.

The Health Centre budget was based on the previous year's activities at the Health Centre, with consideration of the current and forecast activities, whilst the personnel, running and disposable expenses were all negotiated. After this the co-ordinator was anticipated to keep activities to a minimum to achieve a budget saving.

Most of the matters here do not seem soundly carried out with the systems, legal situation and resources available. None were trained for any of these changes.

It seems that the reforms were proposed by the political institution of the Galician Regional Government and contains Galician aspirations. The Financial Manager responsible for the implementation of these changes in his division considered the reforms worthwhile and initially was content about these. We may assume that his senior Regional Managers were of a similar opinion in order for this Financial Manager to work in the way that he did.

When the Financial Manager tried to implement the changes, there were some individuals in the Health Centres who were prepared to consider introducing some changes under the current circumstances. At the end of the study this occurred with 10 Health Centres at Level 1,1 at Level 2 and 1 at Level 3, 15\%. There were 85\% of Health Centres at No Level. We interpret these to mean that there was some agreement about implementing changes in these 12 Health Centres; however, after 4 years this had only progressed beyond the provision 
of data about the Health Centre Level 1, in two cases. These outcomes suggest that the Galician institutional plans only match those of the medical doctors and other professionals in these 12.

The implementation of the institutional reforms was not supported in appropriate ways. There appears to have been no significant increase in resources. There was no training for the Financial Manager about the changes. The budget systems continued largely as before, there were no incentive systems or new organizational decision-making processes for those at the Health Centres. When the two or three Health Centre Co-ordinators did take part beyond Level 1 and had the opportunity to take part in deciding how they wanted to spend the "savings", their ideas were not permissible under Spanish law. The Financial Manager was upset that the anticipated changes to autonomy had not occurred and were not possible under current Spanish law.

\subsection{The Financial Manager}

\subsubsection{Introduction}

This analysis begins after the start of the new system, when the Financial Manager was managing some Health Centres under the old system and other Health Centres at various stages with the new system. The Matrix analysis relates to the personal position that he was in with a Health Centre under the old system and how he acted in his involvement with the Health Centre Co-ordinators in moving a Health Centre to the new system. This section also analyses the Financial Manager's views about the changes he has seen or anticipates in the role of a Health Centre Co-ordinator in moving from the old system to the new system, at the level of the individual. Subsequently, the Financial Manager's views about the co-ordinator will be compared with the co-ordinator's view.

\subsubsection{Financial Manager and his Personal Information-Influence Matrix}

The Financial Manager characterised his role and himself as having independence in decision-making, with superiors listening and involving everyone in a common goal and subordinates helping to solve the different problems that a Health Centre might face.

With the old system the Financial Manager was the person who controlled the nonmedical activities in the Health Centre and the budget for these. He considered himself as the person controlling the situations at the Health Centres. Thus he was in a position of sole control over all activities after discussing matters with his superiors. We might call this sole participation in decisions or autonomy in decisions over a Health Centre.

To demonstrate the changes we accept the experiences of the Financial Manager about the sequence of influence and information that he has used in his work with the Health Centre Co-ordinators to bring about change. These work positions are shown in the Financial Manager's personal Information-Influence Matrix in Fig. 9.

The Financial Manager's (FM) initial position on the Information-Influence Matrix is one of Autonomy with the Local information for decisions. This initial position is shown in Fig. 9 as FM 1. Although referred to as the initial position, it is a position which the Financial Manager will continue to hold up to Level 3.

The Financial Manager noted that at Level 1 in the new system, a Health Centre Coordinator is provided with financial information about the amount spent. He noted that this 


\begin{tabular}{|l|l|l|l|l|l|}
\hline \multirow{2}{*}{ Information } & \multicolumn{5}{|c|}{ Influence } \\
\cline { 2 - 6 } & No influence & Communication & Consultation & Participation & Autonomy \\
\hline $\begin{array}{l}\text { Distant } \\
\text { Information }\end{array}$ & & & & & \\
\hline $\begin{array}{l}\text { Medium } \\
\text { Information }\end{array}$ & & & & & \\
\hline Local Information & & FM 2 Level 1 & FM 3 Level 2 & $\begin{array}{l}\text { FM 4 Level 2 } \\
\text { Level 3 }\end{array}$ & FM 1 \\
\hline No information & & & & & \\
\hline
\end{tabular}

Fig. 9. The Financial Manager's (FM) experiences at Levels 1-3 about his sequence of work with co-ordinators, shown as movements on an Information-Influence Matrix.

provision of financial data to the Health Centre Co-ordinators started a dialogue between the co-ordinator and himself about what the data meant, and what it could be used for. This indicated that he was preparing to be less autonomous in relation to the Health Centre Coordinator at Level 1. The first stage was for him to be in a position of Communication with a Health Centre Co-ordinator providing the Financial Manager with Local Information. The Financial Manager took the decisions. This first stage is shown as FM 2 in Fig. 9.

With the second stage, the co-ordinator was moving from the Communication position to the Consultation position. The Financial Manager took decisions after considering the Health Centre Co-ordinator's views. This second stage is shown as FM 3 in Fig. 9.

In the third stage, the Financial Manager noted that at Level 2 the co-ordinator also had details of personnel capacity for the centre and of the amount of the unspent pre-determined budget. The Health Centre Co-ordinators received guidance about taking on new staff but otherwise the centre's activities were their responsibility. In this way the Financial Manager would have moved from being in consultation with a co-ordinator to being in a participative situation with Local Information and some decisions.

Also at this third stage is a participative situation of Level 3 where the co-ordinator was able to spend a larger amount of the budget savings than at Level 2. Thus both Level 2 and 3 occur at this stage are appear as FM 4 in Fig. 9.

The Financial Manager had found Level 4 and autonomy legally impossible currently, however, this had been discussed and he gave his anticipations about this, which can be compared with our theory. He anticipated that as the participation with a co-ordinator grew towards autonomy, the Financial Manager would have essentially no influence with the Health Centre Co-ordinator in the daily running of affairs. He would no longer be located on the same Information-Influence Matrix, since he would no longer be involved in the daily running of the Health Centre. He would now have a different influence and information relationship with a Health Centre Co-ordinator. This different information and influence relationship is shown as FM 5 in Fig. 10, a new Matrix to demonstrate the start of a new relationship.

These same materials about Levels 1-3 are used to analyse the Financial Manager's positions of influence and information in relation to a Health Centre, as shown in Fig. 11. 


\begin{tabular}{|l|l|l|l|l|l|}
\hline \multirow{2}{*}{ Information } & \multicolumn{5}{|c|}{ Influence } \\
\cline { 2 - 6 } & No influence & Communication & Consultation & Participation & Autonomy \\
\hline $\begin{array}{l}\text { Distant } \\
\text { Information }\end{array}$ & & & & & \\
\hline $\begin{array}{l}\text { Medium } \\
\text { Information }\end{array}$ & & & & & \\
\hline Local Information & & & & & \\
\hline $\begin{array}{l}\text { Local Different } \\
\text { Information }\end{array}$ & & FM 5 & & & \\
\hline No information & & & & & \\
\hline
\end{tabular}

Fig. 10. Anticipated position of the Financial Manager after Health Centre Manager achieves Autonomy at Level 4 Matrix-Financial Manager's view.

He starts with autonomy and local information as FM 1, in Fig. 11, making all decisions about the Health Centre.

This autonomous situation continues whilst he is interacting with the co-ordinator at the communication stage, FM 2, and the consultation stage, FM 3. He will only appear to lose this autonomy once he starts joint-decision-making and moves to participation, FM 4.

\subsubsection{Comparison of Financial Manager's views on his Personal}

Information-Influence Matrix with the theoretical Information-Influence Matrix

A comparison is made between the theoretical Matrix of Fig. 2 containing the anticipated movements of a Financial Manager in relation to the process of change with a co-ordinator and the actual views of the Financial Manager represented in Fig. 9. There are differences.

\begin{tabular}{|l|l|l|l|l|l|}
\hline \multirow{2}{*}{ Information } & \multicolumn{5}{|c|}{ Influence } \\
\cline { 2 - 6 } & No influence & Communication & Consultation & Participation & Autonomy \\
\hline $\begin{array}{l}\text { Distant } \\
\text { Information }\end{array}$ & & & & & \\
\hline $\begin{array}{l}\text { Medium } \\
\text { Information }\end{array}$ & & & & & \\
\hline Local Information & & & & FM 4 & FM 1 \\
& & & & FM 2 \\
\end{tabular}

Fig. 11. The Financial Manager's experiences at Levels 1-3 about his changes in the Information-Influence Matrix-relating to a Health Centre. 
The theoretical Matrix indicated that the Financial Manager would have less influence by moving from autonomy into participation, then consultation, communication and into a different relationship. This is not completely in agreement with the Financial Manager's view.

The Financial Manager indicates that he would retain autonomy over Health Centre decisions until the co-ordinator starts to participate in joint-decisions, when the Financial Manager would be in a participative situation. Until that time he would be in an autonomous position.

The theoretical Matrix was correct to anticipate the movement from autonomy to participation for the Financial Manager, but in practice this occurred through the Financial Manager experiencing communication, consultation and participation with the co-ordinator. This order is the reverse of the anticipated order.

These findings indicate the need to revise the theoretical Matrix to make clear the continued autonomy of the Financial Manager until the co-ordinator takes over and to note the correct order in which changes in influence have occurred.

The theoretical Matrix also indicated a fifth stage, a different relationship for the Financial Manager and the co-ordinator on a separate Matrix, once autonomy occurred. Although this autonomy currently was impossible, the Financial Manager had anticipated such a change. He anticipated this different relationship to be one where he received the total budget data about the Health Centre and its anticipated savings. This means that the theoretical Matrix of the anticipated position of the Financial Manager after a Health Centre Manager achieves autonomy, Fig. 3, and the Financial Manager's own view are identical to his anticipated Matrix in Fig. 10.

\subsubsection{Financial Manager's views related to a Framework of Issues}

As noted in the previous subsection, the findings on the Matrix of the Financial Manager's actual change processes, in relation to a co-ordinator and represented in Fig. 9, are different to the theoretical. Accordingly these findings are now stated in terms of a Framework of Issues for the Financial Manager, in relation to a Health Centre Co-ordinator, being the interpretation of the Information-Influence Matrix shown in Fig. 9.

1. Started in the Local Information-Autonomy, FM 1.

2. In working with the Health Centre Co-ordinator, at Level 1, the Financial Manager provided the co-ordinator with Local Information and decisions indicating a Communication position, FM 2. Financial Manager is still Autonomous.

3. With the start of discussions the Financial Manager moved from the Communication position to the Consultation position of taking decisions after considering the Health Centre Co-ordinator's views, FM 3. Financial Manager is still Autonomous.

4. When matters progressed, the Financial Manager worked from consultation with the co-ordinator to making participative joint-decisions with the co-ordinator sharing Local Information and decisions, FM 4. The Financial Manager is now in the participation stage in Fig. 9, with less autonomy.

5. As the change process came to its conclusion for co-ordinator, the Financial Manager moved into the position of Local Health Centre Information and Communication. FM 5 in Fig. 10. 
When comparing the above Framework of Issues with the theoretical Framework of Issues, items 1 and 5 are the same, but the means of moving from item 1 to 5 were the reversed in practice to that theoretically proposed. Also, the theory needs to be clear that the Financial Manager's autonomy still exists even with Level 3 centres.

\subsubsection{Financial Manager's views about the changes for a Health Centre Co-ordinator represented on a Personal Information-Influence Matrix}

The changes for a Health Centre Co-ordinator are based on the Financial Manager's views about his experiences of change and his anticipations about what would happen if autonomy became possible. The detailed notions were discussed in the previous subsection in relation to the Financial Manager and are not repeated. The objective for the Financial Manager was to change the way in which Health Centres were managed by getting Health Centre staff to agree to implement the new system.

With the old system there was a co-ordinator, who received no information about the expenditures on daily activities and had no influence over these expenditures. Expressed in the context of a personal Matrix for the co-ordinator, the co-ordinator (HCC) was considered to have No Information and No Influence before the start of the new system. This is represented as HCC 1 in Fig. 12. Fig. 12 is composed of the Financial Manager's anticipations about changes with autonomy as well as his experience of changes with the new system relating to a co-ordinator.

With change at Level 1 a co-ordinator was provided with information about the expenditures of the Health Centre and was shown that the activities of his colleagues did affect the amount spent. This put a co-ordinator into a position of Communication from the Financial Manager, who provided a co-ordinator with details of the Local Information and the decisions taken by the Financial Manager. At the position of Level 1 the co-ordinator was in the position of Local Information and Communication. This is represented as HCC 2 in Fig. 12.

With the Level 2 agreement the co-ordinator was provided with data about the spent budget and unspent budget. He was also more involved in discussions with the Financial

\begin{tabular}{|c|c|c|c|c|c|}
\hline \multirow[b]{2}{*}{ Information } & \multicolumn{5}{|c|}{ Influence } \\
\hline & No influence & Communication & Consultation & Participation & Autonomy \\
\hline $\begin{array}{l}\text { Distant } \\
\text { Information }\end{array}$ & & & & & \\
\hline $\begin{array}{l}\text { Medium } \\
\text { Information }\end{array}$ & & & & & \\
\hline Local Information & & HCC 2 Level 1 & HCC 3 Level 2 & $\begin{array}{l}\text { HCC } 4 \text { Level } 2 \\
\text { Level } 3\end{array}$ & $\begin{array}{l}\text { HCC } 5 \\
\text { Level } 4 \\
\text { Unobtainable }\end{array}$ \\
\hline No information & HCC 1 & & & & \\
\hline
\end{tabular}

Fig. 12. The Financial Manager's experiences at Levels 1-3, and anticipations at Level 4 about a Health Centre Co-ordinator's changing role in relation to the daily running of a Health Centre and the changes in information and influence for a co-ordinator, shown as movements on a co-ordinator's Information-Influence Matrix. 
Manager about the decisions the Financial Manager took concerning daily activities. The co-ordinator was becoming more influential over the Financial Manager's decisions. The co-ordinator moved from the Communication position to being consulted in relation to the Financial Manager. This is Local Information and Consultation the situation as at HCC 3 in Fig. 12.

As the ability of the co-ordinator developed so he started to take joint decisions with the Financial Manager and moved to the participation position. This occurred at Levels 2 and 3 , where the co-ordinator received Local Information and was in a Participation position with the Financial Manager, represented by HCC 4 in Fig. 12.

Finally, if the co-ordinator could become responsible for the Health Centre and able to take decisions alone, then the co-ordinator would be in the position of Local Information and Autonomy. This last stage is represented as HCC 5 in Fig. 12.

4.2.6. Comparison of the Financial Manager's views about the changes for a Health Centre Co-ordinator represented on a personal Information-Influence Matrix with the theoretical Information-Influence Matrix

This comparison is between the theoretical anticipated movements of a Health Centre Manager represented in Fig. 4 and those experienced and anticipated by the Financial Manager in Fig. 12. The two Matrices are the same, no differences were found and the theoretical view representation has been verified.

\subsubsection{Financial Manager's views about the Health Centre Co-ordinator related to a}

Framework of Issues

The findings are now stated in terms of a Framework of Issues for the Health Centre Co-ordinator using the representation on the Information-Influence Matrix shown in Fig. 12.

1. Initially the co-ordinator was considered to have No Information and No Influence, HCC 1.

2. On being provided with information the co-ordinator was in the position of Local Information and Communication, HCC 2.

3. With more influence over the Financial Manager's decisions, the co-ordinator moved to the Local Information and Consultation situation, HCC 3.

4. The ability of the co-ordinator developed, he took joint decisions with the Financial Manager and moved to the Local Information and Participation position, HCC 4.

5. When the co-ordinator became responsible for the Health Centre he was in the position of Local Information and Autonomy, HCC 5.

A comparison of the above Framework of Issues, items 1-5, with the theoretical Framework of Issues, items $1-5$, are the same and the theoretical stages of changes have been verified.

\subsection{Health Centre Co-ordinator's views}

\subsubsection{Introduction}

The co-ordinator Anton characterised his role and himself as having at least three relationships with a personal Information and Influence Matrix. His work was with all of the Health Centre's activities, with the budgets set and the expenditures incurred. 


\begin{tabular}{|l|l|l|l|l|l|}
\hline \multirow{2}{*}{ Information } & \multicolumn{5}{|c|}{ Influence } \\
\cline { 2 - 6 } & No influence & Communication & Consultation & Participation & Autonomy \\
\hline $\begin{array}{l}\text { Informt } \\
\text { Information }\end{array}$ & & & & & \\
\hline $\begin{array}{l}\text { Information } \\
\text { Local Information }\end{array}$ & & & & & \\
\hline No information & $\begin{array}{l}\text { Anton 3 } \\
\text { Disposables }\end{array}$ & Disposables & $\begin{array}{l}\text { Anton 1 } \\
\text { Staffing }\end{array}$ & & \\
& & & & & \\
\hline
\end{tabular}

Fig. 13. Anton's Health Centre Co-ordinator's experiences at Levels 1 and 2 about his changing role in relation to the daily running of the Health Centre and the changes in information and influence for a co-ordinator, shown as movements on his Information-Influence Matrix.

\subsubsection{Health Centre Co-ordinator's views and his Personal Information-Influence Matrix}

To represent Anton's personal Information-Influence Matrix shown in Fig. 13, we used three of the areas of influence and information that Anton mentioned about staffing and disposables, and nothing else. This is to illustrate his position and has not attempted to enter into all areas.

Anton appears to have received a lot of information about staffing and has discussed this for some time with the Financial Manager, even before the new system began. With staffing, Anton is considered to be in the Local Information and Consultation position as shown by Anton 1 in Fig. 13.

In the second relationship, disposable materials, he has received information that indicates the expenditure is rising, but he can only express an opinion about it. Here he is considered to be in the Local Information and Communication position as shown by Anton 2 in Fig. 13.

In the third relationship he has no information about the causes of the increased expenditure on the disposable materials and cannot influence the use of disposables. This is considered to be a situation of No Information and No Influence, because he cannot express an opinion. This is shown as Anton 3 in Fig. 13.

\subsubsection{Comparison of Health Centre Co-ordinator's views on his Personal Information-Influence Matrix with the theoretical co-ordinator's Information-Influence Matrix}

The comparison is between the theoretical anticipated movements of a Health Centre Co-ordinator represented on a Matrix in Fig. 4, and the actual views of the co-ordinator in Fig. 13. Anton was in a process of change in the new system at Level 2. In his work he reported having no information and no influence at times, whilst also reporting using local information in situations of communication and consultation. Anton's Matrix is within the theoretical notions outlined for a co-ordinator progressing in the new system. His views have verified the activities being undertaken to move the new system 
and also a large part of the theoretical constructions with Level 2, local information and consultation.

\subsubsection{Health Centre Co-ordinator's views related to a Framework of Issues}

In terms of the Framework of Issues the effect of these changes on the personal Matrix of the Health Centre Co-ordinator are as follows:

1. In the third relationship Anton 3 was in the No Information-No Influence position.

2. In the second relationship Anton 2 is located in the Local Information-Communication position.

3. In the first relationship Anton 1 is located in the Local Information-Consultation position.

These three stages are consistent with those first three stages stated in theoretical Framework of Issues. Clearly Anton has different relationships with information and influence depending upon the area. This is consistent with what we anticipated.

\subsubsection{Comparison of Health Centre Co-ordinator's views on his personal}

Information-Influence Matrix with the Financial Manager's views about a co-ordinator represented on an Information-Influence Matrix

This comparison is between the co-ordinator's views as represented in his personal Information-Influence Matrix in Fig. 13 and the views of the Financial Manager about the changes with a co-ordinator represented by an Information-Influence Matrix in Fig. 12. Anton provided evidence about his experiences up to and including at Level 2. These covered having no information and no influence at times, whilst also reporting using local information in situations of communication and consultation, represented in Fig. 13. These views are consistent with those represented by the Financial Manager in Fig. 12 showing the process of the new system with a co-ordinator starting with no information and no influence and moving to local information and communication and then local information and consultation at Level 2. Thus the views of the Financial Manager and the co-ordinator are similar and consistent with the general movement towards the new system. They both verify the theoretical Matrix for a co-ordinator.

\subsection{Implications of the empirical evidence for the authors' theoretical approach}

\subsubsection{Introduction}

Our previous papers set out our theoretical approaches to study changing information and influence in the context of new systems that were to be introduced into the Galician Health Centres. This theory considered information and influence in the form of personal Information-Influence Matrices for a Financial Manager for a Health Centre Co-ordinator and for the Health Centres as organizations. Finally there were theoretical perspectives in three different areas that required empirical evidence (Purdy and Gago, in press).

The theoretical approaches underpinning this paper have been used since the 1980s and the general approaches to study change in Galician Health Centres were set down (Purdy and Gago, 2003) before we conducted our first conversation with the Financial Manager in September 1999. In 1999 we were given access to the legal and administrative details, so we extended our notions to conform to these and so make our approach one that constituted 
the Galicianization of the theory (Purdy and Gago, in press). It is the Galicianized version of the theory that we are comparing with our empirical materials.

The objective of this paper is to evaluate the evidence collected and relate this to both our own theoretical approaches and later to the approaches others. The three different areas are considered here: the Health Centre Organizations, a Financial Manager and third a Health Centre Co-ordinator.

\subsubsection{Health Centre Organizations}

The empirical data established that Galician Health Centres operate with a Financial Manager who administered 77 then 78 centres. Further, before January 1997 there was an old system but since January 1997 a new system had been available for those at each centre to adopt. This starting date was 21 months before our first conversation. It was possible for a centre to move into particular parts of the new system through agreement with the Financial Manager, and also to return to the old system if desired. The legal understanding of the new system indicated that each Health Centre would become autonomous and that a Financial Manager would gradually lose his influence over running the centre as a co-ordinator took up this work.

The Financial Manager considered his position with the old system in administering the Health Centres to be one of "Total Information" and "Total Influence". In this paper our basic Galician Information-Influence Matrix is in Fig. 1. It contains Information constructs of No Information, Local Information, Medium Information and Distant Information, and, Influence constructs of No Influence, Communication, Consultation, Participation and Autonomy. The flexibility of these constructs, however, has permitted "Total Information" and "Total Influence" to be admitted to the relevant constructs of the basic Galician Matrix to form a new Matrix, Fig. 6. In Fig. 6, the Financial Manager's Information-Influence Matrix shows his Total Information and Total Influence relationship to the 77 Health Centres before January 1997, and, that those Health Centres have No Information and No Influence.

This flexibility to add these constructs is straightforward because the basic approach encourages flexibility as it aims to deal with every Information and Influence situation for individuals and organization. Our first theory paper noted that amongst other notions Total Influence could exist, but Purdy (1987) had chosen not to incorporate this into a Matrix as it indicated a situation of power to take decisions without any obvious influence from others. It was also noted that All Information could exist but was unlikely for most individuals (Purdy and Gago, 2003).

The theory clearly works for the organizational situation because the empirical evidence has allowed the creation of Matrices to show the situations with the Health Centres also at October 1990 - Fig. 7 and December 2001 - Fig. 8. Concentrating on the situation at the end of the study in December 2001, Fig. 8 encompassed that the Financial Manager still had Total Information and Total Influence over all 78 centres. Fig. 8 also demonstrates the situation with the centres. One centre of Level 3 at Participation, one centre of Level 2 at consultation, 10 centres of Level 1 at communication and 66 centres at No Information and No Influence under the old system. After 5 years of opportunity, $85 \%$ of centres had chosen to work with the old system.

The associated movement of information and influence on the Matrix, using the theoretical Health Centres Framework of Five Issues, was confirmed as correct by the experience 
of the Financial Manager for the items 1-4, moving from No Information and No Influence to Local Information and subsequently Communication, Consultation, then Participation. With item 5, Autonomy, it was not currently legally possible, but the Financial Manager noted this had been discussed and he provided his anticipations about this last stage. His view confirmed our theoretical view.

\subsubsection{Financial Manager}

The evidence from the Financial Manager indicated that an Information-Influence Matrix could be constructed about his work, Fig. 9. Fig. 9 shows the three levels of the new system with which he has worked and the Influence that he has exhibited with the co-ordinators. This has been compared with the theoretical movements of a Financial Manager in relation to a co-ordinator, in Fig. 2. The position of the Financial Manager in both Matrices started with Local Information and Autonomy, however, the actual movement of the Financial Manager was to Communication, Consultation and then Participation with a co-ordinator. The theoretical order was into Participation, Consultation and finally Communication. In view of this the theory here needs to be revised to the actual path of the Financial Manager.

The previous subsection noted why the Financial Manager could only provide his discussed anticipations about his likely situation after a Health Centre and its co-ordinator achieved Autonomy. He noted that he would be in a different relationship with the coordinator, with the co-ordinator reporting to him, and this is shown in Fig. 10. When this is compared with the theoretical position of Fig. 3, they appear to be same. Thus parts of the theory have been confirmed but some need amending.

The associated movement of information and influence on the Matrix, using the theoretical Financial Manager's Framework of Five Issues, was confirmed as correct by the experience of the Financial Manager for the items 1 Autonomy and 5 Different relationship. The theoretical movements of item 2 - Participation, 3 - Consultation and 4 - Communication were incorrect and should be of item 2 - Communication, 3 - Consultation and 4 Participation. It should be noted that the Financial Manager went through the same stages as the theory but in a reverse order. So the theory needs to be revised to the actual order.

\subsubsection{Health Centre Co-ordinator}

The theoretical movements of a Health Centre Co-ordinator on an Information-Influence Matrix appear in Fig. 4. We obtained two sets of data which corroborated our theoretical view. The Financial Manager's experiences with Levels 1-3 confirmed the movement of a co-ordinator from No Information and No Influence through Local Information and Communication, Consultation and then Participation. As noted earlier, the Financial Manager provided his anticipations about Autonomy, and all of these are represented in Fig. 12. In this way the changes of Fig. 12 are the same as the theoretical shown in theoretical coordinator Matrix Fig. 4. The theory is verified with experience as far as participation, and anticipations concerning Autonomy.

The co-ordinator's experiences are represented in his personal Matrix of Fig. 13. The co-ordinator experienced only Levels 1 and 2 and with these confirmed the actual views of the Financial Manager, Fig. 12 and the theoretical Fig. 4.

The associated movement of information and influence on the Matrix, using the theoretical co-ordinator's Framework of Five Issues, was confirmed as correct by the experience of 
the Financial Manager for the items 1-4, and by the co-ordinator for the items 1-3. Item 5, the move to Autonomy was anticipated by the Financial Manager and verified in that way.

\subsection{Implications of findings to authors' norms, previously cited studies and other work}

\subsubsection{Authors' norms}

The implications of our findings for our theoretical approach have been discussed, so the other relevant findings are discussed here. The findings will be considered in relation to the authors' norms, then the relevant previous studies already cited (Purdy and Gago, in press) and finally other literature relating the organizational findings to a wider context. In particular comparisons are made with a study of operational museum change in Canadian local government. This is to develop more insights into the outcome of the Galician changes. Galician institutional plans for the Health Centres to change to a new system had been matched by medical and professional staff in 12 out of 78 centres. Of these, 10 centres were at the communication stage - Level 1, one at the consultation stage - Level 2 and one at the participation stage - Level 3 .

The previous paper demonstrated our research position and accepted the Galician legal anticipations at face value as we construed these. Our personal Information and Influence Matrices for a Financial Manager and Health Centre Co-ordinator, and, an organizational Information and Influence Matrix for Health Centres, along with appropriate Frameworks of Issues, incorporated our norms which accepted the overall optimistic narratives about change (Purdy and Gago, in press). We found similar optimism from the Financial Manager, who eventually became very frustrated at the failure of the system to be able to bring about change. We accepted his views. In this respect there were similarities between us.

A basic part of the legislation for the new system was that Health Centres would be able to achieve autonomy. Although the possibilities about autonomy had been discussed by the Financial Manager with colleagues, the current Spanish laws prevented this from occurring. Perhaps this disappearance of a main objective has discouraged staff from taking part.

The Financial Manager's anticipations about changes in the administration of Health Centres included more cooperation with Health Centres and saw their co-ordinator as a link between the staff in the centres and Regional Management. Perhaps this was not appropriate for Health Centre staff.

The Financial Manager indicated that when he commenced change with a co-ordinator, there was communication of his decisions about the daily activities and the provision of data concerning the amount spent by the Health Centre. From the context of information provision, this amended situation could be an unsettling experience for the co-ordinator. The co-ordinator was being told about decisions over which he had no control and also told about the cost of these decisions, which he could not affect. This does not appear to be very satisfactory for any co-ordinator to be in this situation as it could produce a sense of a lack of control. This could be another strong reason why co-ordinator withdrew and most centres not to start the new system.

There was also the fact that there were no additional resources for these new systems. In this new system, at Level 2 and beyond, budgets were prepared for each centre and agreed with a co-ordinator. One objective of the new system was to make "savings" on the budget and allow co-ordinator at Level 2 have some influence in how this would be used. In three 
centres that, at some time during the study, had worked at Level 2 this opportunity had been available. The co-ordinators had preferred to use these savings with staff substitutions, but this was difficult for the Financial Manager to agree to because the Spanish hypothecated tax system did not permit discretionary spending outside of a category. Maybe the new system was aimed at saving money. Perhaps these were strong reasons for co-ordinator not to advance in the system or for the majority of centres to continue with the old system.

Another apparent problem with the new system was that medical staff would only have a small increase in their salary for becoming an administrator, but would have more administrative resources, particularly computers, to release time for medicine.

In the previous paper, the retos of legislation was considered an intangible, qualitative, developmental aspect of life, likely to be difficult to carry out and a stimulus in the work area. We anticipated receiving details about the various retos in operation with different people and situations, but retos were not mentioned. Perhaps the implied retos, for all of those involved with Health Centres, was to work harder without additional resources or pay to achieve the Galician legal aspiration. Perhaps the Financial Manager considered the project of change to a new system as retos for himself.

At the start of the field study, it was arranged that we would be given access to some co-ordinator at different levels. When it finished in December 2001, despite the best efforts, access had been denied to more than one co-ordinator. The relevance of only one co-ordinator needs to be considered in context. First, in relation to the numbers involved, at the end there were there were only two co-ordinator who had reached level two, indicating consultation, apart from Anton, the one who had been interviewed and had subsequently left the service. Thus we had interviewed a third of the people who had been involved at Level 2, and these findings confirmed the work of the Financial Manager and his views, as well as our own theory. It is correct that there were 10 co-ordinator at Level 1, communication, and these may have added some different insights if some had been interviewed, but all would have been at a lower level than we had obtained materials for.

One further aspect about the interview with the co-ordinator is that we work with personal construct psychology and its emphasis on the individual. In our view this one co-ordinator has provided us with appropriate evidence about the situation of such an individual undertaking the new system at Level 2. That interview has provided sufficient evidence for our study which was designed to be combined with the Financial Manager. It has also been some corroboration of the Financial Manager's views.

\subsubsection{Previously cited studies}

Almost all organization studies are different in their underpinning. For this paper our collection of data was aimed at collecting personal views and factual views to use with our theoretical approaches. These specific requirements make it difficult to make very simple comparisons with other studies and vice versa. A US study dealt with various attributes of performance and involvement by the team members. Teams performed best when members took part in setting the measurement targets and received more compensation (Scott and Teissen, 1999). In Galicia, Level 2 and 3 agreements between the Health Centre and the Financial Manager determined their activities and their budgets and involved very little or no change in remuneration. Any budget savings were limited to specific areas of use and not used completely as co-ordinator wanted. 
Some findings were similar to those of the UK Centre for Decision-Making Studies (1979) showing that Galician management controlled the information provision process. The Health Centre Co-ordinator indicated the potential changes which might be fostered in centres with employee information provision and the related influence on decisions. He noted that some appropriate data was used in some meetings that he had held with his colleagues.

The Financial Manager indicated his agreement with and commitment to the proposed changes towards the provision of information to the Health Centre Co-ordinator and gradual greater influence of the co-ordinator on the daily running of the centre. This was similar to the views of Goodlad and the lower and middle UK managers' willingness to make information available and alter the system of its budget use with employees (Goodlad, 1984). In the Goodlad study the changes did not start because senior managers did not permit this. In Galicia the changes did not start in 45 Health Centres, this was not due to the senior managers, but more likely because, it was impossible with Spanish law to have autonomy, and, tax was hypothecated, so when raised for one purpose could not be used for another.

The Health Centre Co-ordinator indicated his use of appropriate data which was discussed at meetings. He noted that although the data was valid for him, at times he did not understand the terminology and had sought and received willing explanations from the Regional Office. These actions were indicative of a move towards the wider dissemination of data throughout the Health Centre, a more "open" form of data provision and management, and similar to that previously found with large UK companies (Purdy and Gago, in press).

The Galician legal aspirations had been prevented by Spanish law and health policies. These differences are similar to the European Economic Community's formulation of policy about information provision to employees and their involvement especially with participation. During the early stages of its development, the notions promoted were of employee participation, however, participation was excluded from the final Directive (European Communities Commission, 1994).

Arnold found US companies apparently created autonomy and employee involvement in the late 1980s, but this was subsequently rescinded in the early 1990s. She noted that this excursion into autonomy was really intensified Taylorism (Arnold, 1999). In the 5 years covered here, autonomy was not legally possible. We did find that the majority of the Health Centres, 45, had not moved from old system, whilst 21 moved to Level 1 and then rejected this and returned to old system. Overall approximately $85 \%$ had no changed arrangements after 5 years.

Arnold noted that the ending of the autonomy schemes destroyed trust. We cannot say what has happened because the Spanish law prevented moves to autonomy. Not withstanding, perhaps this lack of suitable legislation has allowed staff in many Health Centres to have experienced a lack of trust.

\subsubsection{Other studies}

This Galician episode is a study in change relating to a section's Financial Manager, where his Health Centre Co-ordinators, would have taken the responsibility for dealing with non-medical matters moving towards consultation and eventual autonomy. The employees of the Health Centre, in which they worked, would have decided to change its administrative processes to the new system. In fact this has only occurred in a few centres. We are dependent 
upon the views of a Financial Manager about the reasons for these events and seek other studies to help improve our insights about the organizational.

Armstrong comments on the situation with groups of workers, "cell proprietors", involved in change in a manufacturing company. He noted the workers did not have any property rights but they did have responsibility for confronting the competition and satisfying customers. These matters were 'responsible autonomy', a control strategy which included flexible working. He clarified this to be operating at two levels, the higher company levels where there was freedom to find new ways of achieving company objectives, whilst the lower levels were free to find new ways of achieving the targets derived from the higher company levels (Armstrong, 2006).

It would seem that the Financial Manager and perhaps some of the Galician medical health practitioners had been involved in searches for new ways of delivering the new systems, so that a minority were doing that. Perhaps these were at the higher organizational level of the Regional Directors, since we found no evidence of retos, or targets, or additional information about specific changes in objectives.

The paper by Oakes et al. (1998) considered the theoretical position of personnel involved in Alberta's museum service. They noted the curators in the Museum Division constituted a curatorial profession and were recognised as the technical personnel that constituted the taken-for-granted elements of cultural capital of that field. If that profession could no longer hold on to this body of knowledge, the field would become open to question, then the cultural capital of the field would be lost (Oakes et al., 1998).

We can explain the movements and the lack of movements of the Galician medical health practitioners, using those theoretical concepts used by Oakes et al., if we accept that these practitioners constitute a profession in the same sense used by Oakes et al. (1998). There were 12 Health Centres that had adopted the new system, perhaps the new systems did not present these practitioners with any matters which they considered as a threat to their professional work. One Health Centre each had embarked on some Level 2 and Level 3 activities, whilst 10 had moved to Level 1.

On the other hand, using the same concepts, perhaps the majority of the Galician medical health practitioners considered that changing to the new system would create changes in their professional field and capital which they considered unacceptable. One Health Centre had moved to the Level 2 before returning to old system, 19 had achieved the first level but then returned to old system, whilst 46, including 1 new centre, had not moved and remained at old system.

There is further theory from Oakes et al. that is helpful to explain our findings. They considered the Museum Division as a field of restricted production, and that such fields were relatively autonomous as their orientation was primarily internal. There was circularity here because the field had the cultural capital to control its own internal processes and criteria, which in turn allowed those working in the field to have greater autonomy over what constituted their work (Oakes et al., 1998).

In our study, the Galician medical health practitioners may be considered to constitute a field of restricted production, where they were autonomous in their activities and were primarily internally focussed. In 66 Health Centres they used this autonomy to prevent change to the new system and in 12 there were some new systems. This would indicate a different type of autonomy already exists. 
In their conclusions, Oakes et al. draw attention to the matter of generalisations across different actual fields; however, they consider in all fields there are similarities as they all involve the manoeuvrings over positions and capital, and that finally, actors are complicit in their own control and can change themselves and what is valued in their field of operation (Oakes et al., 1998).

All of these matters would appear to be active in our study, where some Galician medical health practitioners have moved towards the new systems, but the majority have not.

\section{Summary and conclusions}

The authors are interested in the ways accounting information and the influence associated with accounting information, are used in organizations by the individuals involved. They became aware of impending changes to Galician Health Centres with the use of centre co-ordinator to facilitate the eventual autonomy of the centre in relation to the Regional Health Authority. Two earlier papers provided our theoretical antecedents for a study of change in three areas involving an individual Financial Manager's personal Information-Influence Matrix, a co-ordinator's personal Information-Influence Matrix and an organizational Health Centres Information-Influence Matrix. Each of these change areas were theoretically anticipated and placed into stages through a Framework of Five Issues for the three areas (Purdy and Gago, 2003, in press).

This paper provides the brief theoretical setting to these three areas, presents the collection of data, between September 1999 and December 2001, from a Financial Manager and a Health Centre Co-ordinator, then analyses these materials and relates the findings first to our own theoretical approaches, and second to the approaches of others. Our agreement with the Financial Manager was to discuss matters with an appropriate number of centre co-ordinators in the new system. There was no agreement to discuss with any personnel in the old system. The theory was concerned with change in these three areas with the introduction of the new system, and the interactions of a Financial Manager and a co-ordinator, and consequently the total outcomes for all Health Centres in the new system.

Our conversational methods secured the data required, which we were able to interpret in terms of information and influence for all three areas on the appropriate Information and Influence Matrices and for the Frameworks of Five Issues. Again these basic theoretical approaches have been validated as constructions which have a usefulness in everyday situations, here with Galician managers.

The specific theoretical approaches were stated as the stages of progress with changes in each item of a Framework of Issues. These very largely have been supported and certainly to the extent that current Spanish legislation allowed changes to occur. The depth of the analysis for each Matrix and Framework of Issues is fine and quite lengthy, so here the theory is affirmed without too much detail, but there is detail in the explanations of the differences and extensions to the basic Galician Information-Influence Matrix. The great flexibility of the conceptual notions underpinning an Information-Influence Matrix are displayed in dealing with specific situations.

Our initial interest was with the ways in which the Financial Manager and co-ordinator interact in this change situation, but we also covered the organizational as the overall changes 
with the Health Centres. We begin with the organizational in January 1997, when the new system for centres started, but we were unaware of this until September 1999. Before January 1997, with the old system, the Financial Manager had Total Information and Total Influence over 77 centres, making the centres in a position of No Information and No Influence. The conceptual bases of the Matrix are such that it was possible to insert both of these items, at appropriate places on the basic Galician Information-Influence Matrix. These insertions added to the explanatory ability of the organizational Matrix. The position of No Information and No Influence for any centre indicates that it is not in the new system.

At the time of the first conversation with the Financial Manager the new system was anticipated to constitute four new levels of Local Information and Influence. Level 1 was equivalent to our Communication, Level 2 - our Consultation, Level 3 - our Participation and Level 4 - our Autonomy. Thus our notions about the stages of Information and Influence appeared to fit these proposed changes. At that time 32 centres had moved into the new system: 30 at Level 1, 2 at Level 2, and 45 in the old system.

When the study ended in December 2001 there were 10 at Level 1, 1 at Level 2, 1 at Level 3 , and 66 with the old system. There was also one centre which had reached Level 2, but its co-ordinator left and the centre returned to the old system. There was also recognition from the Financial Manager, after much discussion with his colleagues, that under the existing Spanish legislation it was impossible for a centre to move to a position of Autonomy. Based on these discussions he provided his views about how such an Autonomous centre would be handled. These anticipations of the Financial Manager about Autonomy fitted sensibly with our own notions about it. Thus the basic Galician Information-Influence Matrix was validated by experience up to Participation and through discussion to Autonomy. At the same time the Framework of Five Organizational Issues was validated through the existence of the stages of Local Information to Communication, Consultation and Participation, and the Autonomy through the Financial Manager's anticipations.

The second theoretical area concerns the Financial Manager and his interactions with a centre co-ordinator. His theoretical personal Information-Influence Matrix contained the same constructs of information and influence as the organization. The Financial Manager's experience and anticipations were able to be represented on this Matrix.

The progress of the Financial Manager in the theoretical Framework of Five Issues anticipated that the Financial Manager's progress would be with (1) Local Information and his influence starting in Autonomy, would move to (2) Participation, then (3) Consultation, then (4) Communication and finally (5) would be a new relationship with a co-ordinator and on a separate Matrix.

His actual progress on his Framework of Five Issues was (1) Local Information and Influence starting in Autonomy, however, he moved to (2) Communication, (3) Consultation and (4) Participation. Also, since it was legally impossible for Autonomy to be given to a co-ordinator, we had the Financial Manager's considered view, that, if self-management had occurred then he would have been at (5) in a new relationship with a co-ordinator and thus a separate personal Information-Influence Matrix for the Financial Manager. This indicates that the Financial Manager agreed with the items 1 and 5 in the theoretical Framework of Issues. The items 2, 3 and 4 in his actual personal Information-Influence Matrix were in the reverse order to the theoretical. 
The theoretical Financial Manager's Framework of Five Issues has been revised for future work to be: (1) Local Information and his influence starting in Autonomy, would move to (2) Communication, (3) Consultation, (4) Participation and (5) a new relationship with a co-ordinator and on a separate a Financial Manager Matrix.

The third area deals with a centre co-ordinator and his interactions with the Financial Manager. His theoretical personal Information-Influence Matrix contained the same constructs of information and influence as the organization and the Financial Manager. The co-ordinator's experience and anticipations were able to be represented on this Matrix. The progress of the co-ordinator in the theoretical Framework of Five Issues was (1) No Information and No Influence, (2) Communication, (3) Consultation, (4) Participation and (5) Autonomy. This Framework of Five Issues was validated from the experience of the Financial Manager and the centre co-ordinator as far as item 4. Again the Financial Manager's view about Autonomy, after discussions, was similar to the theoretical position.

Currently, we have validated all three areas as far as Participation, the actual experience of Autonomy has to wait for our future work or for others. The theoretical Frameworks of Five Issues, including the revised personal one for the Financial Manager are available for further testing.

We now move beyond our theoretical notions into other matters which have come from the findings and relate to our norms. Essentially, after 5 years of the possible new system there were 66 centres with the old system and 12 in the new system. Clearly change did not occur in the way that Financial Manager had anticipated when we had our first conversation. Ultimately, the optimistic Financial Manager who we had spoken with in 1999, at the end in 2001 was very frustrated because the whole Spanish system had failed to bring about the changes outlined in the Galician legislation.

The factual reasons we advance for this situation come from the Financial Manager, but we have our own interpretations and comments on several facets of our findings. We have interviewed one co-ordinator and have not been able to access other co-ordinators. People who remained with or returned to the old system, were not a part of our agreement for we had anticipated working with several co-ordinators.

Our perspective believes that there are likely to be a number of reasons, why some co-ordinators have come forward to take these positions, why some centres have moved to the new systems and stayed there, why some centres have moved to new systems and then returned to the old and why the majority have stayed with the old systems.

The overarching sets of facts, which probably are inter-related are, Autonomy for Health Centres is legally impossible in Spain and the hypothecated tax system means that taxes raised for a specific purpose have to be used for that purpose. Thus with a budget, there were no possibilities of co-ordinators using funds in the ways they considered would be in the best interests of the centre, unless their use coincided with the tax laws. In these ways the major objectives of the legal change towards Autonomous Health Centres with more budget autonomy are not available to any person in Spain. We consider that these have been potentially large reasons for the lack of centres working with the new system.

Our theoretical interpretation of the Galicianization of Health Centres was an optimistic one, and it was an optimistic project for the Financial Manager. At the end of our 
study, 12 out of 78 centres were in the new system. This feels almost like a pilot project has been undertaken. At the same time it also represents some success for the Financial Manager.

Moving to a slightly different matter, we wonder if the style and ideas of the Financial Manager were not suitable for the majority of centres and personnel. He was left to his own intuition and not offered any training for his role-change. He considered the co-ordinator as a link between the centre and the region. The starting approach to change, that he outlined, was to communicate information to centre co-ordinators telling them about their expenditures. It was acknowledged that at times, a co-ordinator had to make expenditures which he could not control, yet a co-ordinator had been informed of matters over which he had no control, with a view to reducing expenditures. It is possible that individuals did not find this an acceptable experience or even unpleasant, and so withdrew, or were unprepared to become engaged in the new system.

The financial manger mentioned that with the new system he had provided suitable information which a co-ordinator would understand in relation to budgets. The evidence from the co-ordinator does not entirely match this view, when he noted that the information was acceptable and understandable, but at times he had to ask about the meaning of terms from persons in the Regional Office. This situation of a person "understanding" information, and even using it but requiring help in some way, was found previously in a study of UK ward sisters and accounting data (Purdy, 1993c).

Further matters related to funding. There were no additional resources available for the new system. It was anticipated that most co-ordinators would be from the medical profession, and the small amount they would receive on becoming a co-ordinator would not be a financial incentive, as they would be able to earn larger amounts in other jobs. Also, the only physical compensations for working as a co-ordinator were the prospects of more computers to run the administration. Perhaps these matters were not attractive.

The new system produced a plan and a budget for a centre, which the co-ordinator was anticipated to run the centre with. One object for a co-ordinator was to make savings by not spending parts of the budget, and then later have some influence in how these savings would be spent for the centre's benefit. Maybe this system was not acceptable to the majority who did not change from the old system. This spending of savings was forced into matters that the tax had been raised for.

In a related sphere, the legislation envisaged that the qualitative retos would be used in the change processes. We had no idea what these might have been, but nothing was mentioned in conversations. Perhaps the whole project was a retos for the Financial Manager. Maybe the co-ordinators found it a retos to become involved and enjoyed the influence they exercised.

Apart from the Financial Manager we interviewed one Level 2 co-ordinator, from the three co-ordinator, that had moved to at least Level 2. This means that we interviewed a third of those with experience of Level 2 . There was a great deal of similarity between notions about change from the co-ordinator and the Financial Manager, providing some mutual support for their views.

Of great relevance is our theoretical approach to our work and the use of the psychology of personal constructs with its emphasis on the activities of the individual (Kelly, 1955). Our prime interest has been the construing of individuals in this change process towards the new system. We have empirical materials from one Financial Manager and one co-ordinator, 
which are those individuals' constructions about themselves in their job. This has provided us with sufficient materials to verify, refute or alter our theoretical constructs. Our basic work has been achieved with Participation. Autonomy, currently legally impossible, can be carried forward for future work in the knowledge that we already have some empirical views from the Financial Manager which agree with our theoretical views.

The objective of the field study was to collect data from a Financial Manager and a co-ordinator to verify or not verify our three theoretical areas. Even though we were aware of earlier studies that held some affinities with our approaches (Purdy and Gago, in press), we did not attempt to obtain any data that either simulated their methods or their types of data collected, in order to compare matters. We have a few comparisons we can sensibly make with other studies.

Earlier studies suggested that management controlled the information provision process (Purdy and Gago, in press), and this happened in our study with the Galician management. In the Galician case the Financial Manager was committed to the new system, but at the national stage suitable changes did not occur.

The Galician legislation promoted the notion of Autonomy, but our study found this legally impossible, though Participation was occurring with the Financial Manager and some co-ordinators. There are some similarities between this non-appearance of autonomy and the non-appearance of participation in the final proposals about employees' information and influence provisions (European Communities Commission, 1994).

Some notions related to Autonomy have featured in a number of other studies. In one study Arnold noted that that ending an autonomous scheme destroyed trust (Arnold, 1999). We have no evidence that trust has been affected the absence of Autonomy, but the Financial Manager felt very frustrated at the failure of the whole system to bring about change.

A more useful paper, to help us explore potential reasons for the outcomes of the Galician change initiative, is some of the theory used to consider the position of personnel involved in Alberta's museum service from Oakes et al. (1998) in their study of change. If we assume that the Galician medical practitioners constitute a profession, including holding a body of knowledge and cultural capital, then a couple of matters may be deduced in parallel to Oakes et al.'s notions. First, if these practitioners experience a threat to their body of knowledge then perhaps they would move to the new system, as in fact 45 centres made no movements. At the same time similar practitioners in other centres may not have experienced such a threat and have moved to the new system.

Further we use some of our Galician materials to follow Oakes et al.'s (1998) notions about field restricted production. If these medical practitioners are a field of restricted production, then these practitioners were already autonomous. This indicates that the practitioners have a form of autonomy already in their Galician Health Centres. It maybe this autonomy of the medical practitioners has been valued more by them than that held out by Galician legislation.

We have used this paper to examine some empirical materials for comparison with and to verify our theoretical approaches of Matrices of Information and Influence for Organizations, and the actions of a Financial Manager and a Co-ordinator, and the associated movements of each of the three on their Frameworks of Five Issues. This study has created a new stream of empirical research and we would encourage further studies to explore the roles of Information and Influence including Participation and Autonomy. 


\section{Acknowledgements}

Susana Gago thanks the Spanish Government for funds from SEJ2004-08176-C02-02. Derek Purdy thanks the Management Control Association for a travel grant. An earlier version of this paper was given at the Sixth International Management Control Systems Conference, Management Control Association, Edinburgh Business School, July 2004. The authors thank colleagues for their supportive comments, in particular Dominique Bessire, Université d'Orleans, Annick Bourguignon, ESSEC, Cergy-Poutoise, and Krister Bredmar, University of Kalmar. The Financial Manager involved in the empirical work for our study read that paper, accepted our thinking, Frameworks, the methods of data collection, the data collected, methodologies of analysis, and, the preliminary conclusions that we drew about our field study. In this way he generously helped us with the empirical and theoretical development of our area. We are grateful to those we interviewed or spoke with about our work in this paper. This is our representation of their everyday activities which we have interpreted in our way.

We thank Tony Tinker and the particular reviewer for their comments on an earlier draft which has helped us to improve this paper. Responsibility for this paper remains with us.

\section{References}

Armstrong P. Ideology and the grammar of idealism: the Caterpillar controversy revisited. Critical Perspectives on Accounting 2006;17:529-48.

Arnold PJ. From the Union Hall: a labor critique of the new manufacturing and accounting regimes. Critical Perspectives on Accounting 1999;10:399-423.

Centre for Decision-Making Studies. Report to the Leverhulme Trust on company information to employees project. London: Tavistock Institute of Human Relations; 1979.

European Communities Commission. European Works Council Directive. Official Journal of the European Communities, No. L254; 1994.

Goodlad JB. Budgetary control: non-managerial employee involvement. London/Liverpool Polytechnic: Institute of Cost and Management Accountants; 1984.

Kelly GA. The psychology of personal constructs. New York: WW Norton; 1955.

Oakes LS, Townley B, Cooper DJ. Business planning as pedagogy: language and control in a changing institutional field. Administrative Science Quarterly 1998;43:257-92.

Parker RJ, Kyj L. Vertical information sharing in the budgeting process. Accounting, Organizations and Society 2006;31(1):27-45.

Purdy DE. Employee involvement: moving towards workplace decision-making. Administrator; 1987. p. 4-11.

Purdy DE. An examination of the rationales for providing financial and management information to employees in the context of the UK: towards a general rationale of the process from a management perspective. Discussion Papers in Accounting and Finance (No. 11), University of Reading; 1988.

Purdy DE. Natural learning in Committee B. Management Education and Development 1991;22(Part 1): 60-70.

Purdy DE. Accounting, controls, change and the perceptions of managers: a longitudinal study of ward units in a teaching hospital. Financial Accountability and Management 1993a;9(1):45-66.

Purdy DE. Information and the participation of employees in Great Britain. In: Antoine M, editor. L'information des salaries au Royaume-Uni et en France. Presses de l'Universite de Paris-Sorbonne; 1993b. p. 33-60.

Purdy DE. Ward Sisters and financial management accounting. Financial Accountability and Management 1993c;9(4):279-86.

Purdy DE, Gago S. Public sector managers handling accounting data: a UK framework validated in Spain. Financial Accountability and Management 2002;18(3):233-60. 
Purdy DE, Gago S. Towards a framework to study influence and accounting use. Critical Perspectives on Accounting 2003; 14:663-78.

Purdy DE, Gago S. Extending influence and accounting use: developing the frameworks to incorporate Galician legal matters about the proposed healthcare changes with managers and organizations for empirical study. Critical Perspectives on Accounting 2007;18:707-36.

Scott TW, Tiessen P. Performance measurement and managerial teams. Accounting, Organizations and Society 1999;24:263-85.

Spekman RE. Influence and information: an exploratory investigation of the boundary role person's basis of power. The Academy of Management Journal 1979;22(1):104-17.

Wall TD, Lischeron JA. Worker participation: a critique of the literature and some fresh evidence. New York: Mc Graw-Hill; 1977. 